\title{
Multi-Organ Teratogenesis Sequels of Bigger Size Particles Colloidal Silver in Primate Vertebrates
}

Pani Jyoti Prakash ${ }^{* 1}$, Singh Royana ${ }^{2}$ and Pani Sankarsan ${ }^{3}$

${ }^{1}$ Department of Anatomy, Faculty of Medicine, Institute of Medical Science and Research, Karjat, Bhivpuri, India

${ }^{2}$ Department of Anatomy, Institute of Medical Sciences, Banaras Hindu University, Varanasi, Uttarpradesh, India

${ }^{3}$ Deapartment of Surgery, Institute of Medical Science and Research, Karjat, Bhivpuri, India

*Corresponding author: Prakash PJ, Department of Anatomy, Faculty of Medicine, Institute of Medical Science and Research, Karjat, Bhivpuri, India, Tel: 8433668356; E-mail: jyotiprakashimsbhu@gmail.com

Received date: February 21, 2018; Accepted date: March 12, 2018; Published date: March 16, 2018

Copyright: ( 2018 Prakash PJ, et al. This is an open-access article distributed under the terms of the Creative Commons Attribution License, which permits unrestricted use, distribution, and reproduction in any medium, provided the original author and source are credited.

\begin{abstract}
Back ground: In this most recent, update global arena for consumers products most of the daily applications of bigger silver nano particles (20 to 100 nano meter range) are effected as anti-viral and anti-parasitic agents in clinical medicine and diagnosis which is a positive feedback. However, the major negative feedback of bigger size silver nano particles on human, animal and primate vertebrate body is multisystem teratogenicity focuses.

Material and methods: This study was designed to investigate teratogenic effects of bigger size nano silver which is poly vinyl pyrollidone coated and sodium borohydride stabilized. For this we injected its colloidal solution form in to pregnant female Swiss albino mice of different breeding colonies (10 from each group) in repeated oral gavages manner with nanosilver-71-1900.8 nano meter range at a dose of $14,19 \mathrm{mg} / \mathrm{kg} / \mathrm{b} . \mathrm{w} . / \mathrm{day}$ with sham control treated by anionic double distilled water for 7-18 gestational days (12 days). Then dead animals are then anaesthetized and operated by ventral laparotomy on day 19. Fetuses were collected for open eye and hand lens morphological verification to locate various teratogenic anomalies.
\end{abstract}

Result: We found multi system teratogenicity in treated group fetuses like Syndactyly, Oligodactyly, Polydactyl, meningo myelocele, closed type neural tube deformity, skeletal deformity like flat ribs, absence of bony segments or cleft, vertebral deformity like scoliosis, absence of long bones or its parts or mal developments or even mal fusion. We also found Central nervous system teratogenic effects like malformation of cerebrum, hippocampus and cerebellum. Histological teratogenic effects are observed in form of honey comb deformity and cell vacuolization in Central nervous system were significantly correlated with oxidative stress.

Conclusion: Our findings suggest that bigger size silver nano particles induce an impairment of multi system and Central nervous system functions and teratogenic sequels by increasing oxidative stress and hampering nutrition in those body parts. The use of bigger silver nano particles for medical and diagnostic purposes henceforth requires careful consideration, particularly if it involves exposure of the human multi system and Central nervous system as it may evokes multi system teratogenicity in offspring's where dose directly proportional to intensity.

Keywords: Silver-polyvinyl pyrollidone; Sodium borohydried; Nano particles; CNS teratogenicity; Multi system teratogenicity; Oxidative stress

\section{Introduction}

Silver Nano particles (AgNps) with diameters of less than $100 \mathrm{~nm}$ and above $20 \mathrm{~nm}$ have unique nature because of bigger size. Research involving the overall and individual assessment of multi-system teratogenic effects of bigger size AgNps has generated a lot of interest on behalf of scientists since the intensity of teratogenic sequels produced are dose and size-dependent. Examples of such teratogenic effects are multi-system wise related anomalies which incubates only in delivered fetuses of F1 generation such as cleft lip, cleft palate, mal formed snout anomalies and oligodactyly etc. Dose-dependent teratogenic effects are believed to be a result of the obstruction and hamper of nutrition in pregnant mother. Moreover bigger size silver nano particles exhibit dose-dependent teratogenicity focuses in F1 generation fetuses after oral application in pregnant mouse chosen from different breeding colonies. [1] In spite of extensive use of bigger size silver nano particles in medical fields there is even lacuna in update data regarding its teratogenic impact on animal and human health. The bigger size silver nanoparticles also execute teratogenic effects on some of the anaerobic bacteria and viruses. [2] However, very little is known about the teratogenic effects of bigger nano-sized silver particles. Dose, size and surface area are thought to be important determinants of teratogenicity [3]. Unlike larger particles, silver nanoparticles are likely to travel through organs, and can produce adverse teratogenic effects, including teratogenic effects on the central nervous system (CNS). Silver nanoparticles translocate to the systemic circulation and the CNS in a unique manner due to their large size and large surface area. Silver nanoparticles can cross the blood-brain barrier (BBB) [4]. Together, these results suggest that bigger size AgNps might have detrimental effects on the mammalian brain. The brain is highly vulnerable to oxidative stress due to its high metabolic rate, bigger size AgNps increase brain oxidative stress, inducing 
deficits. Sometimes accidental poisonings with ionic or colloidal silver also occur or self or even parental inflicted poisonings with ionic or colloidal silver also occur. Such poisonings are often manifested as argyria, a blue-grey discoloration of the skin that is caused by silver deposits [5-7]. Scientist East and his other associates in the year 1980 found retention of silver ion and metals in a 47 year old woman who already suffered from argyria. They used radioactive tracer element for this, retention of silver ionic element was found to be $18 \%$ of an orally administered dose. When comparing ionic silver and nano particulate silver after oral administration, the latter was shown to is less bio available based on higher faecal excretion and lower absolute levels in organs following head to head investigations $[8,9]$. As a teratogenic effect oral route injected ionic and nano silver colloid found to be deposited in a wide range of organs. The most well described depositional effect is the blue grey discoloration of the human skin that is observed during Argyria [5,7], with addition to skin, nano silver has been abnormally detected in numerous organs following repeated oral administration, including liver, kidneys, brain, skin, pelt, spleen, eyes, muscles, blood, small intestine, stomach, lungs, bladder, prostate, tongue, teeth, salivary glands, thyroid, parathyroid, heart, pancreas and duodenum as multiple teratogenic consequences. [8,10,11-20] Goebel and his associate observed small size nano silver in the brain of a 72 year old woman suffering from Argyria. However, no silver was observed within the central nervous parenchyma [10]. Scientists also found the migration of small size nano silver from mothers to child following an oral dose of 8 to $10 \mathrm{~nm}$ range silver nanoparticles, suggesting that silver can cross the placental barrier [21].

Data regarding the persistence of silver in the body following oral administration are limited; scientists investigated silver retention in a 47-year-old woman who already had Argyria. By using a radioactive tracer, the amount of silver following oral absorption was found to remain constant for up to 30 weeks [22]. Some other scientists also found that orally administered silver nitrate solution caused small and bigger nano size silver deposition in the eyes as granules that were still present 12 months after administration as a teratogenic consequence [23].

\section{Death doses of silver nano metal}

Scientists observed an anti-smoking mouthwash containing silver nitrate as the active ingredient which stimulates multi system teratogenic effects [24]. In rats, the LD50 was found to be $280 \mathrm{mg}$ of silver/kg of b.w. following oral administration. In rabbits, the LD50 was found to be $800 \mathrm{mg}$ of silver $/ \mathrm{kg}$ of b.w./day. Scientists also detected silver nitrate at concentrations of $24 \mathrm{mM}$ (corresponding to $308 \mathrm{mg}$ of silver $/ \mathrm{kg}$ of bw2) in the drinking water to induce death over the course of a few days [25]. Hydrocolloid silver nanoparticles have certain potential teratogenic effects upon animal embryo which caused raised concern over public. Scientist reported repeated ovo administration of 50 particles per million hydrocolloids of nano particles of silver and its ions and alloys with copper did mildly or null influence fatality, growth and development of 25 days old chicken embryos [26,27].

\section{Cardiac teratogenicity of silver nano metal}

A research scientist observed left ventricular hypertrophy in rats [28]. Olcott suggested that the hypertrophy of the rat heart was caused by high blood pressure due to the deposition of silver in the basement membranes of the renal glomeruli [28]. Scientists reported histopathological findings in the spleens (decreased red pulp and increased white pulp) and kidneys (necrosis) in rats that were orally administered 1 or $2 \mathrm{mg} / \mathrm{kg}$ of bw/day of $70 \mathrm{~nm}$ silver nanoparticles for 30 days. Decreased red pulp potentially affects red blood cell clearance; whereas necrosis of glomerular cells, the Bowman's capsule and proximal tubular cells in the kidney potentially affect body fluid homeostasis [29].

\section{Multi teratogenicity of chemical agents, drugs and nano metal}

Some of the market available chemical agents, drugs and nano metal also induce multi teratogenicity such as mal development, dead born, bleeding and abortion [30] In USA major health problem persist in form of embryological and developmental defects, 3 to $5 \%$ of fetuses are found to be congenital and embryological ailment because of unusual ingestion of chemical agents, drugs and nano metal by mother [31]. It is been calculated that 10 to $12 \%$ of human anatomical and embryological teratogenicity resulted from the devastative actions of oncology, anticancer or chemotherapy drugs, viruses and other environmental factors [32]. A scientist in 2004 era also assessed that defects attributable to drug therapy represent about $1 \%$ of congenital defects of known etiology [33].

The teratogenicity risk of silver nano on multi system of body of primate vertebrate was evaluated, because of the accidental exposure to bigger size nano silver the mother intensely affected and transfers teratogenic sequels to further offspring. We tried to collect worldwide adequate research report on teratogenicity of nano silver for successful evaluation of nano silver teratogenicity, in this present study.

\section{Liver kidney teratogenicity of bigger size silver nano metal and fatal virulence}

Medical and biological research reports have proved that, many medical and prosthetic devices release Ag+ ions into the blood and its accumulate in the liver and kidney after passing through portal entry which after it cause liver and kidney teratogenicity and toxicity which is also called internal organ teratogenicity that leads to fatal consequence [33].

\section{Neuronal teratogenicity}

Teratogenicity focuses on fetuses of human due to colloidal silver nano particles of bigger size oral repeated ingestion is not sufficiently evaluated. Colloidal silver nano particles of bigger size oral repeated ingestion causes blood-brain barrier (BBB) dysfunction and neuroteratogenicity in human fetuses after accidental ingestion, Most of the previous researches on silver nanoparticles neurotoxicity demonstrated, bigger size colloidal silver nanoparticles through repeated gavages oral route when induced into the circulatory channels arises blood brain barrier malfunction, neuroglial cell swelling with teratogenicity changes in fetuses after transfer from mother via placenta, it also causes additional neuronal degenerative teratogenicity in fetuses $[34,35]$. Cerebral inflammatory teratogenicity in fetuses caused by accidental ingestion of either chemical or physical factor or accidental ingestion of particle colloidal silver of bigger size also arises blood brain barrier teratogenicity, up raised permeability of tiny and safety brain blood vessels. This neuronal teratogenicity and degenerative focuses are usually associated with compromised blood brain barrier [34,36,37]. Severe teratogenicity focuses such as blood brain barrier disruption usually involves in cerebral inflammatory teratogenicity sequels link diseases in fetuses after bigger size colloidal silver nano repeated oral application in mother. The intensity of such 
teratogenicity is directly proportional to amount of colloidal silver ingestion [38,39]. When bigger size colloidal silver nanoparticles get in contact with upper surface of blood in blood vessels it chemically hyper reacts and leads to inflammogenic teratogenicity. This type of effects usually seen inside blood vessels of cerebrum due to this blood brain barrier dysfunction occur and teratogenic response like neuroglial cell deformity and neuronal cell teratogenicity and degenerative changes occur [34,35]. Neurological ailments are unusual consequence of silver teratogenicity which was recently reported in a 75 to 80-year-old man who had a history of self-medication with colloidal silver and was presented with myoclonic seizures [38].

Since there are very negligible and sparse available data on the teratogenicity of bigger size nano silver in consumer products of mouse embryos, the teratogenic effects of nano silver on multi system in mouse embryos was evaluated in the present study for the this time to restructure a good manuscript.

\section{Past glimpses of miscellaneous teratogenicity events by repeated ingestion of bigger size silver ion}

Rare and sparse historical data's available to demonstrate that oral ingestion of bigger size ionic silver or colloidal ionisable silver compounds in primigravida stage causes infertility. Also it causes hampered fetal development and growth, or even maldevelopment in any further offspring genus and species. An intrauterine injection of 1 to $2 \%$ Silver nitrate solution at a dose of $10 \mathrm{ml}$ when injected into multiple (more than 10) pregnant apes of cynomolgus variety aged about 25 to 50 days pregnancy condition caused early uterine bleeding and hemorrhage and medical termination of pregnancy, but when out of those more than 10 animals two animals when sexually established relationship the female became pregnant again without any complication and delivered a healthy offspring [39].

Blue baby syndrome or Argyria is one of the classical negative response of ionic silver, two of the eminent scientist had reported this for the first time in a woman who had ingested a total dose of 6 to $7 \mathrm{gm}$ of silver nitrate over a period of 1 year time and showed Argyria symptoms after the first six months of exposure [40]. Scientist also observed irritation in respiratory tract, colicky pain in abdomen and diminished night vision in industrial workers who exposed to silver nitrate solution fume and silver oxide dusts over a period of one to ten years [41]. Some of the scientists conducted research work in industrial area observed blue discoloration of the conjunctiva and cornea in some industrial workers after repeated silver oxide dust and silver nitrate solution fume inhalational exposure [42].

An eminent toxicologist observed in a case study of a 51- year-old man and found corneal and conjunctival blueness that exposed to silver ionic compounds [43]. Another scientist observed a case study of a 59 to 60-year-old man who was distressed from dermal and faces color change. He had ingested colloidal silver two to three times per year for two years and showed endocrine disruptions, such as hyperlipidemia, hypertension and diabetes as well as blue-grey facial signs [44]. Scientists reported teratogenic effects of nano silver colloid depend on the route of ingestion. Most of the researches demonstrated that many medical and surgical devices and instruments loaded with silver could release silver ions these ions transmigrated through the blood circulation and accumulate principal organ liver and kidney. It may induce hepatic and renal teratogenicity and may lead to death in some cases of extreme exposure to a certain dose of nano silver [45]. The present study showed the effects of bigger size nano silver teratogenicity on multi system of body of fetuses of pregnant Swiss Albino mice. The present results indicate that exposure to 14 and 18 $\mathrm{mg} / \mathrm{kg}$ b.w of bigger size silver nano particles from 7 to 18 th days of gestation of pregnant Swiss Albino mice decrease the weight and length of embryos and induce multi system teratogenicity and strongly influence on the skeletal system. For this reason we conducted this study.

\section{Material and Methods}

\section{Availability of data and materials}

Fresh delivered fetuses of Pregnant Swiss Albino mice which are available at Animal house of Department of Anatomy Institute of Medical Sciences, Banaras Hindu University, Varanasi Uttarpradesh, and India are utilized for experiment for this manuscript.

\section{Methods}

To conduct the research on underlying teratogenic effects of bigger size nano silver which is poly vinyl pyrollidone coated and sodium borohydride stabilized, we injected bigger size particle colloidal silver form in to pregnant female Swiss albino mice of different breeding colonies (10 from each group) in repeated oral gavages manner at early morning at 8.30 am with nanosilver-71-1900.8 nano meter range at a dose of $14,19 \mathrm{mg} / \mathrm{kg} / \mathrm{b}$.w./day with sham control treated by anionic double distilled water for 7-18 gestational days (12 days). Then dead animals are then anaesthetized and operated by ventral laparotomy on day 19. Fetuses were collected for open eye and hand lens morphological verification to locate various teratogenic anomalies. From each group all fetuses were selected and included in this experiment.

All most 100 fetuses were examined by powerful hand lens and dissecting microscope from each group meticulously for this verification of various teratogenicity focuses. This research is performed abide by appropriate rules and regulation of pregnant animal slutering and fetuses examination. Central animal ethical committee of Banaras Hindu University issued permission for this experiment which includes pregnant mother mice killing, liberation of fetuses and verification of various embryological anomalies in them including control and treated. The number issued by CAEC to us is No./Dean/2014/CAEC/614 dated 30.05.2014.

\section{Results}

We found multi system teratogenicity in treated group fetuses like Syndactyly, Oligodactyly, Polydactyl, cleft lip, cleft palate, Meningo myelocele, closed type neural tube deformity, skeletal deformity like flat ribs, absence of bony segments, vertebral deformity like scoliosis, absence of long bones or its parts or mal developments or even mal fusion. We also found CNS teratogenic effects like malformation of cerebrum, hippocampus and cerebellum. Histological teratogenic effects are observed in form of honey comb deformity and cell vacuolization in CNS were significantly correlated with oxidative stress. Our findings suggest that bigger size silver nano particles induce an impairment of multi system and CNS functions and teratogenic sequels by increasing oxidative stress and hampering nutrition in those body parts. 
Citation: Prakash PJ, Royana S, Sankarsan P (2018) Multi-Organ Teratogenesis Sequels of Bigger Size Particles Colloidal Silver in Primate Vertebrates. J Cytol Histol 9: 501. doi:10.4172/2157-7099.1000501

Page 4 of 18

\section{Successful characterization of bigger size silver nano by Transmission electron microscopy}

Characterization of colloidal silver nano was done using TEM exploration. The solution was exposed to tungsten grid after being dried into powder form and characterization done. 2 types of sizes estimated during the TEM process $71 \mathrm{~nm}$ ranges and $1900.8 \mathrm{~nm}$ ranges (Figure 1).

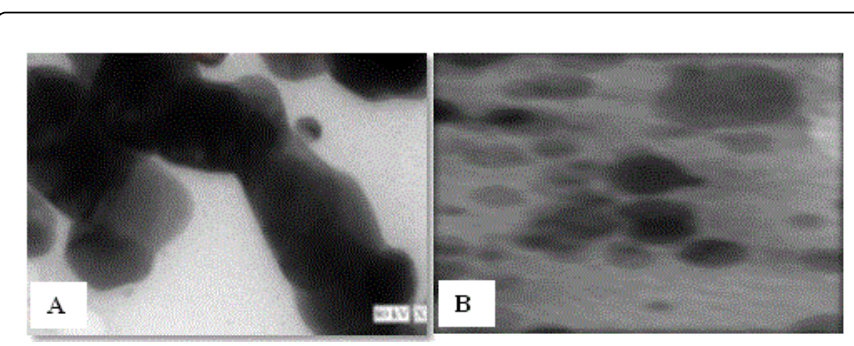

Figure 1: (A) TEM picture of $1900.8 \mathrm{~nm}$ size ranges silver nano, (B) TEM picture of $71 \mathrm{~nm}$ size ranges silver nano.

\section{Resorption}

All mothers exposed to sham control (Anionic double distilled water intake), 14 and $19 \mathrm{mg} / \mathrm{kg} /$ day bigger size AgNps colloidal solution repeated oral gavages treated and group. Resorptions are evaluated from fetuses of control and same treated mother group after ventral laparotomy with observation by powerful hand lens and dissecting microscope.

Treated group fetuses after resorption evaluation compared with all fetuses of sham control group. Out of almost 100 fetuses from each treated group $14 \mathrm{mg} / \mathrm{kg} /$ day bigger size AgNps colloidal solution treated group showed $42(42 \%)$ fetuses were suffered from resorption from $19 \mathrm{mg} / \mathrm{kg} /$ day bigger size AgNps colloidal solution treated group showed 57(57\%) fetuses were suffered from resorption. Control group also showed negotiable resorption rate and compared well with treated groups, (7 fetuses found Resoprtion from control group) (7\%) (Figures 2 and 3 ).

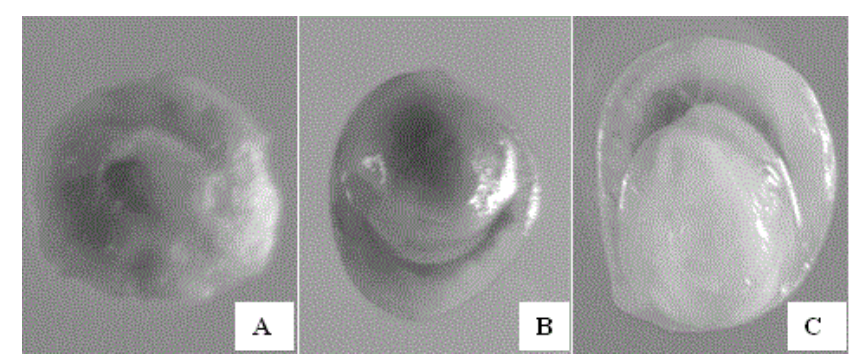

Figure 2: (A) Resorption from control group, (B) Resorption from $14 \mathrm{mg} / \mathrm{kg} /$ day bigger size AgNps colloidal solution treated group, (C) Resorption from $19 \mathrm{mg} / \mathrm{kg} /$ day bigger size AgNps colloidal solution treated group.

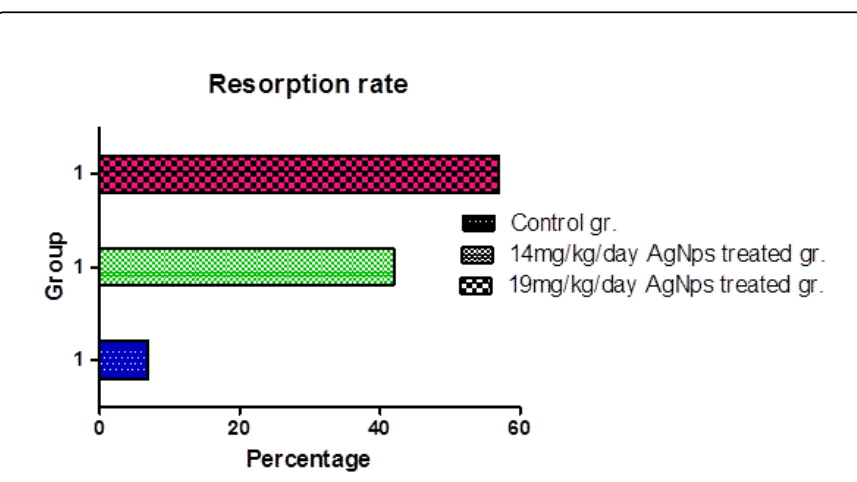

Figure 3: Represents resorption rate in percentages from control and treated group.

\section{Intra uterine growth retardation (I.U.G.R.)}

Intra Uterine Growth Retardations are evaluated from fetuses of control and same treated mother group. Treated group fetuses after Intra Uterine Growth Retardations evaluation compared with all fetuses of sham control group. Out of 66 fetuses from each group, 14 $\mathrm{mg} / \mathrm{kg} /$ day bigger size AgNps colloidal solution treated group showed $30(45.45 \%)$ fetuses were suffered from Intra Uterine Growth Retardations from $19 \mathrm{mg} / \mathrm{kg} /$ day bigger size AgNps colloidal solution treated group showed $40(60.60 \%)$ fetuses were suffered from Intra Uterine Growth Retardations.

Control group also showed sparse Intra Uterine Growth Retardations rate and compared well with treated groups. (5 fetuses found Intra Uterine Growth Retardations from control group) (7.57\%) 1 maldeveloped Swiss Albino fetus and total product of conception including amniotic membrane and placenta observed severe hemorrhagic mass within the membrane (1.51\%) (Figures 4 and 5).

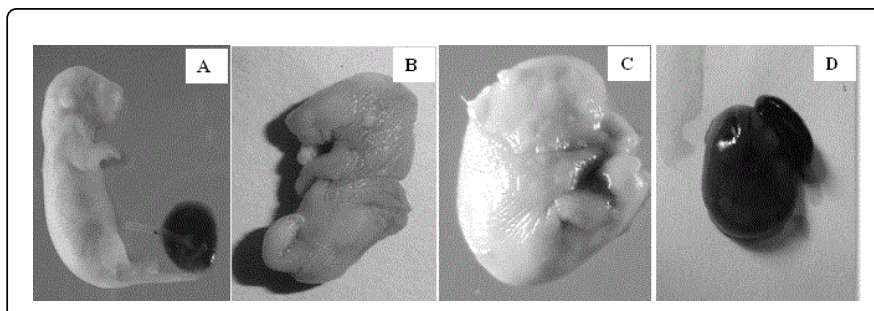

Figure 4: (A) I.U.G.R. from control group, (B) I.U.G.R. From 14 $\mathrm{mg} / \mathrm{kg} /$ day bigger size AgNps colloidal solution treated group, (C) I.U.G.R. From $19 \mathrm{mg} / \mathrm{kg} /$ day bigger size AgNps colloidal solution treated group (D) Hemorrhagic fetus. 
Citation: Prakash PJ, Royana S, Sankarsan P (2018) Multi-Organ Teratogenesis Sequels of Bigger Size Particles Colloidal Silver in Primate Vertebrates. J Cytol Histol 9: 501. doi:10.4172/2157-7099.1000501

Intra Uterine Growth Retardation rate

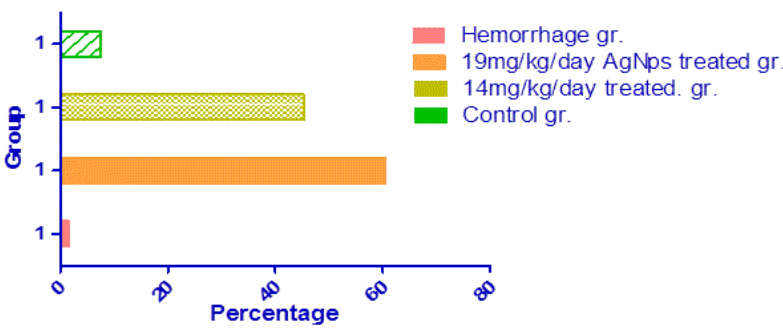

Figure 5: Represents I.U.G.R. rate in percentages from control and treated group.

\section{Limb malformation (polydactyl, oligodactyly)}

Limb malformations like polydactyl and oligodactyly are evaluated from fetuses of control and same treated mother group. Treated group fetuses after polydactyl and oligodactyly percentages evaluation compared with all fetuses of sham control group. Out of 57 fetuses from each treated group, $14 \mathrm{mg} / \mathrm{kg} /$ day bigger size AgNps colloidal solution treated group showed 14 (24.56\%) fetuses were suffered from polydactyl and 9 (15.78\%) fetuses were suffered from oligodactyly from $19 \mathrm{mg} / \mathrm{kg} /$ day bigger size AgNps colloidal solution treated group showed 19 (33.33\%) fetuses were suffered from polydactyl and 12 (21.05\%) fetuses were suffered from oligodactyly.

Control group also showed very negotiable percentages of polydactyl and oligodactyly rate and compared well with treated groups. (4 and 5 fetuses found polydactyl and oligodactyly each from each control group) (7.01\% and 8.77\%) (Figures 6 and 7).
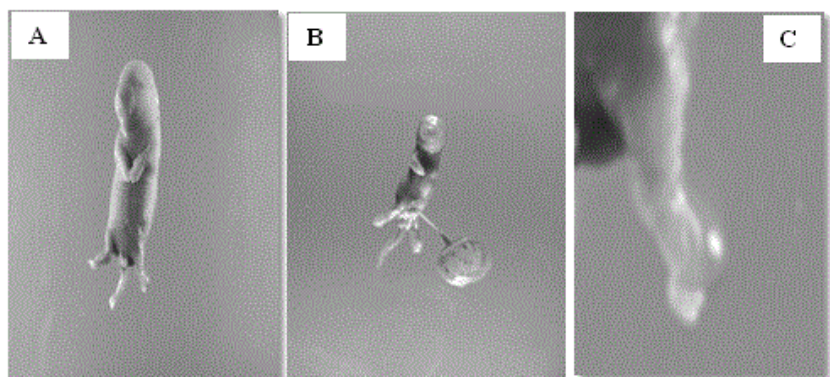

Figure 6: (A) Polydactyl from control group, (B) Polydactyl from 14 $\mathrm{mg} / \mathrm{kg} /$ day bigger size AgNps colloidal solution treated group, (C) Oligodactyly from $19 \mathrm{mg} / \mathrm{kg} /$ day bigger size AgNps colloidal solution treated group.

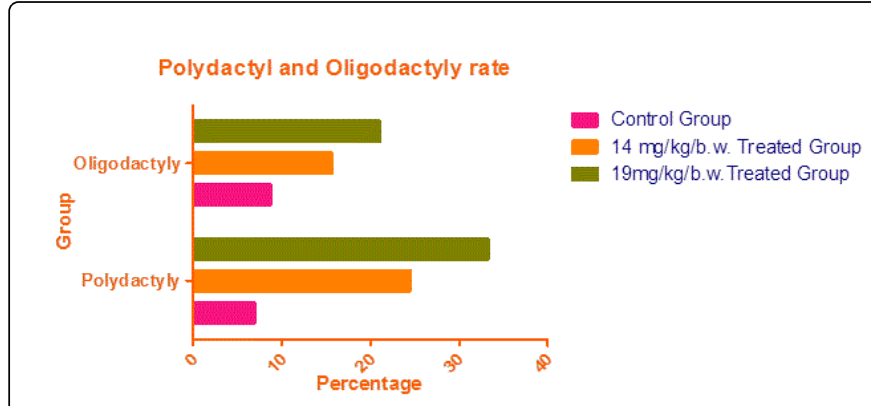

Figure 7: Represents Polydactyl and Oligodactyly rate in percentages from control and treated group.

\section{Phocomelia and proboscis}

Phocomelia and Proboscis are evaluated from fetuses of control and same treated mother group. Treated group fetuses after Phocomelia and Proboscis percentages evaluation compared with all fetuses of sham control group. Out of 57 fetuses from each group, $14 \mathrm{mg} / \mathrm{kg} /$ day bigger size AgNps colloidal solution treated group showed 7 (12.28\%) fetuses were suffered from Phocomelia and Proboscis from 19 $\mathrm{mg} / \mathrm{kg} /$ day bigger size AgNps colloidal solution treated group showed 10 (17.54\%) fetuses were suffered from Phocomelia and Proboscis.

Control group also showed very negotiable percentages of Phocomelia and Proboscis and compared well with treated groups, (3 fetuses found Phocomelia and Proboscis from control group) (5.26\%) (Figures 8 and 9).

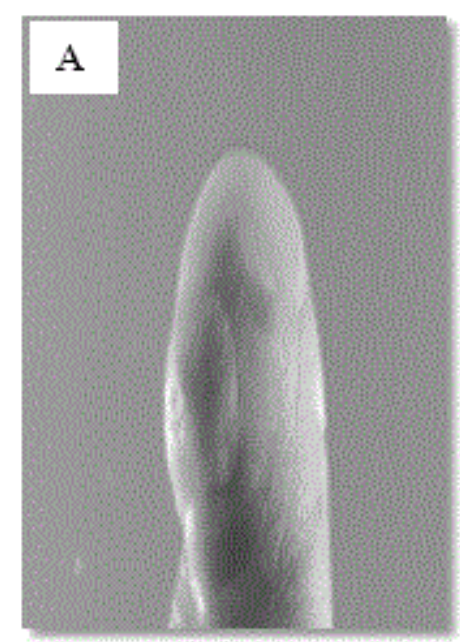

Figure 8: (A) Phocomelia and Proboscis from 19 mg/kg/b.w. AgNps group. 


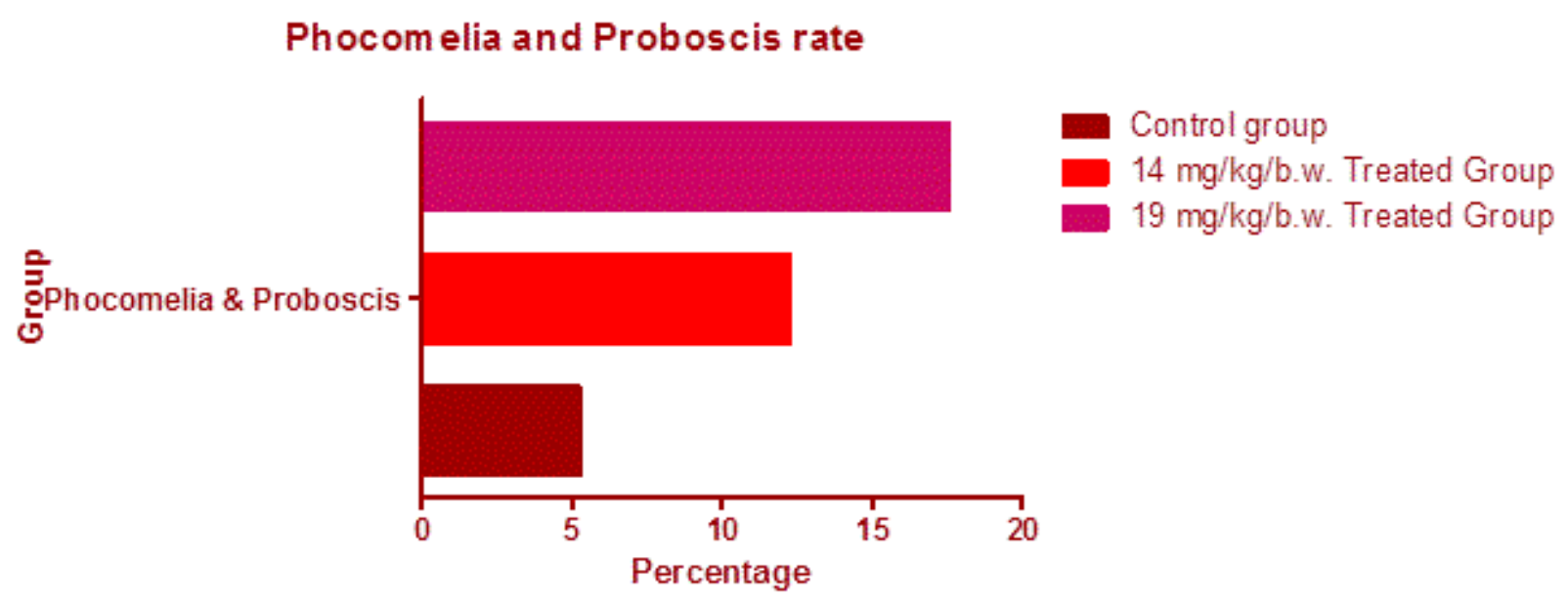

Figure 9: Represents Phocomelia and Proboscis rate in percentages from control and treated group.

\section{Closed type neural tube defect}

Closed type neural tube defects are evaluated from fetuses of control and same treated mother group. Treated group fetuses after closed type neural tube defect percentages evaluation compared with all fetuses of sham control group. Out of 57 fetuses from each group, $14 \mathrm{mg} / \mathrm{kg} / \mathrm{day}$ bigger size AgNps colloidal solution treated group showed 3 (5.26\%) fetuses were suffered from closed type neural tube defect from 19 $\mathrm{mg} / \mathrm{kg} /$ day bigger size AgNps colloidal solution treated group showed $5(8.77 \%)$ fetuses were suffered from closed type neural tube defect. Control group also showed very negotiable percentages of closed type neural tube defect and compared well with treated groups, (2 fetuses found closed type neural tube defect from control group) (3.50\%) (Figures 10 and 11).

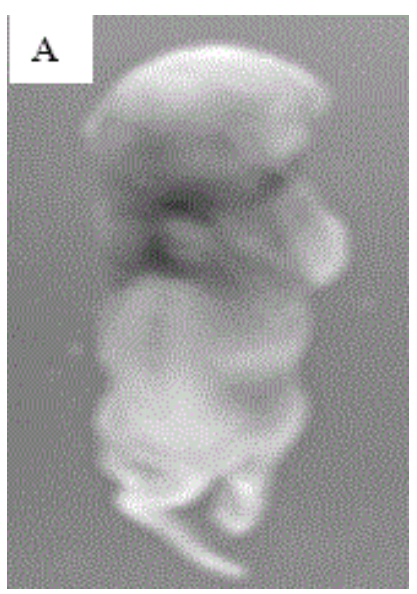

Figure 10: (A) Close type neural tube defect from $19 \mathrm{mg} / \mathrm{kg} / \mathrm{b} . w$. AgNps group.

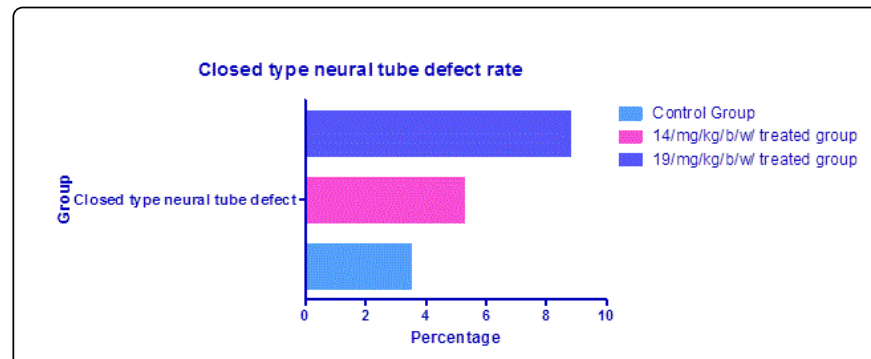

Figure 11: Represents closed type neural tube defect rate in percentages from control and treated group.

\section{Amelia}

Amelia's are evaluated from fetuses of control and same treated mother group. Treated group fetuses after Amelia percentages evaluation compared with all fetuses of sham control group. Out of 57 fetuses from each group, $14 \mathrm{mg} / \mathrm{kg} /$ day bigger size AgNps colloidal solution treated group showed 2 (3.50\%) fetuses were suffered from Amelia from $19 \mathrm{mg} / \mathrm{kg} /$ day bigger size AgNps colloidal solution treated group showed 3 (5.26\%) fetuses were suffered from Amelia.

Control group also showed extreme negotiable percentages of Amelia and compared well with treated groups (1 fetus found Amelia from control group) (1.75\%) (Figures 12 and 13). 


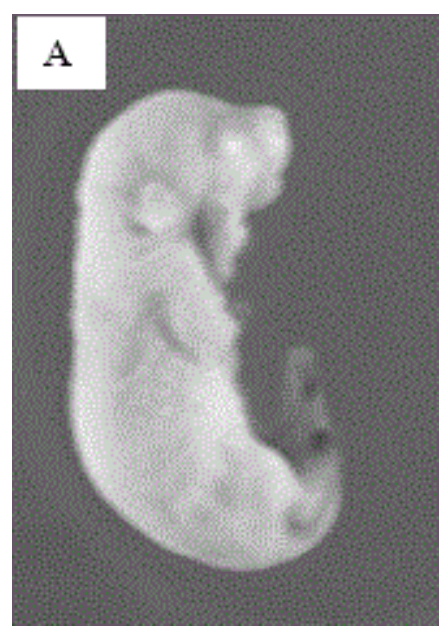

Figure 12: (A) Amelia defects from $14 \mathrm{mg} / \mathrm{kg} / \mathrm{b} . w$. AgNps group.

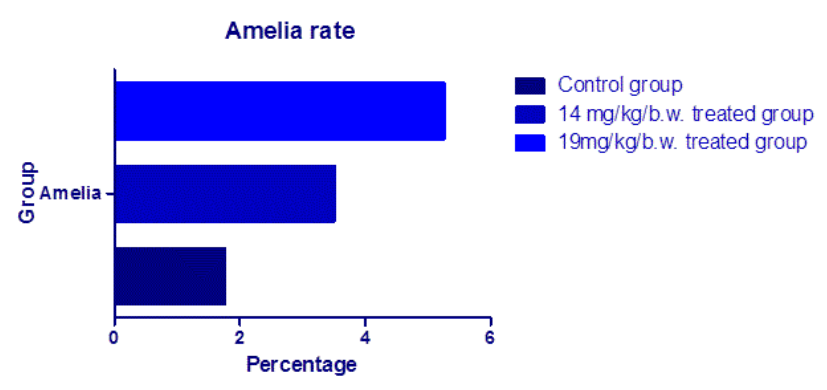

Figure 13: Represents Amelia rate in percentages from control and treated group.

\section{External limb malformation (Syndactyly)}

External limb malformation like Syndactyly's are evaluated from fetuses of control and same treated mother group. Treated group fetuses after External limb malformation like Syndactyly percentages evaluation compared with all fetuses of sham control group. Out of 57 fetuses from each treated group, $14 \mathrm{mg} / \mathrm{kg} /$ day bigger size AgNps colloidal solution treated group showed $13(22.80 \%)$ fetuses were suffered from External limb malformation like Syndactyly from 19 $\mathrm{mg} / \mathrm{kg} /$ day bigger size AgNps colloidal solution treated group showed 18 (31.57\%) fetuses were suffered from external limb malformation like Syndactyly.

Control group also showed very negotiable percentages of External limb malformation like Syndactyly rate and compared well with treated groups. (5 fetuses found External limb malformation like Syndactyly from each control group) (8.77\%) (Figures 14 and 15).

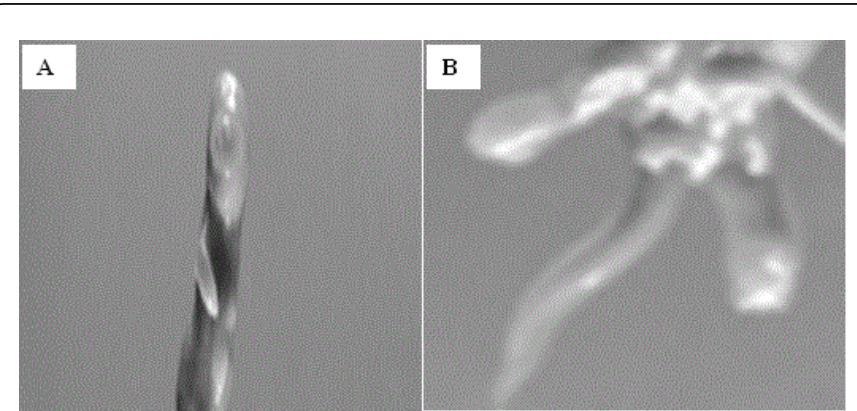

Figure 14: (A) External limb malformation like Syndactyly from 14 $\mathrm{mg} / \mathrm{kg} / \mathrm{b} . \mathrm{w}$. AgNps group, (B) External limb malformation like Syndactyly from $19 \mathrm{mg} / \mathrm{kg} / \mathrm{b} . \mathrm{w}$. AgNps group.

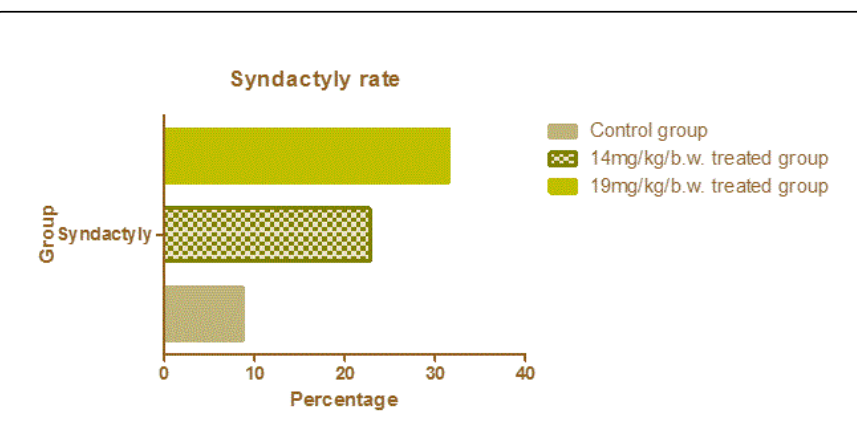

Figure 15: Represents Syndactyly rate in percentages from control and treated group.

\section{Foot and tail vein hemorrhage}

Foot and tail vein hemorrhages are evaluated from fetuses of control and same treated mother group. Treated group fetuses after Foot and tail vein hemorrhage percentages evaluation compared with all fetuses of sham control group. Out of 57 fetuses from each group, 14 $\mathrm{mg} / \mathrm{kg} /$ day bigger size AgNps colloidal solution treated group showed $6(10.52 \%)$ fetuses were suffered from Foot and tail vein hemorrhage from $19 \mathrm{mg} / \mathrm{kg}$ /day bigger size AgNps colloidal solution treated group showed $12(21.05 \%)$ fetuses were suffered from Foot and tail vein hemorrhage.

Control group also showed very negotiable percentages of Foot and tail vein hemorrhage rate and compared well with treated groups. (2 fetuses found Foot and tail vein hemorrhage from each control group) (3.50\%) (Figures 16 and 17). 
Citation: Prakash PJ, Royana S, Sankarsan P (2018) Multi-Organ Teratogenesis Sequels of Bigger Size Particles Colloidal Silver in Primate Vertebrates. J Cytol Histol 9: 501. doi:10.4172/2157-7099.1000501

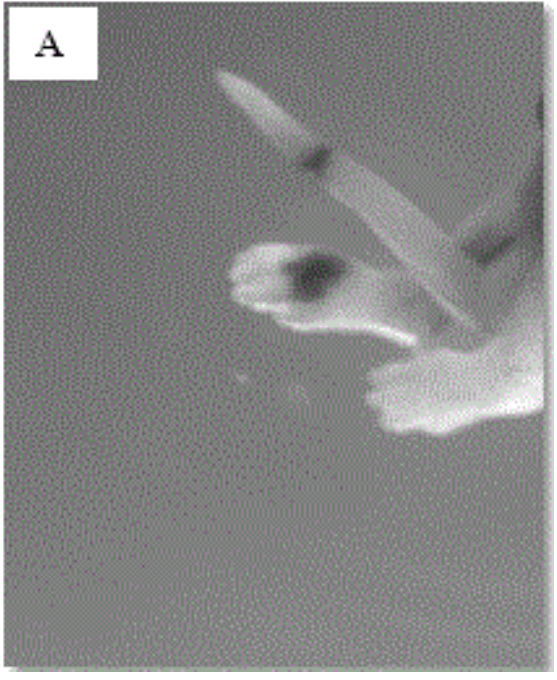

Figure 16: (A) Foot and tail vein hemorrhages from $19 \mathrm{mg} / \mathrm{kg} / \mathrm{b} . \mathrm{w}$. AgNps group.

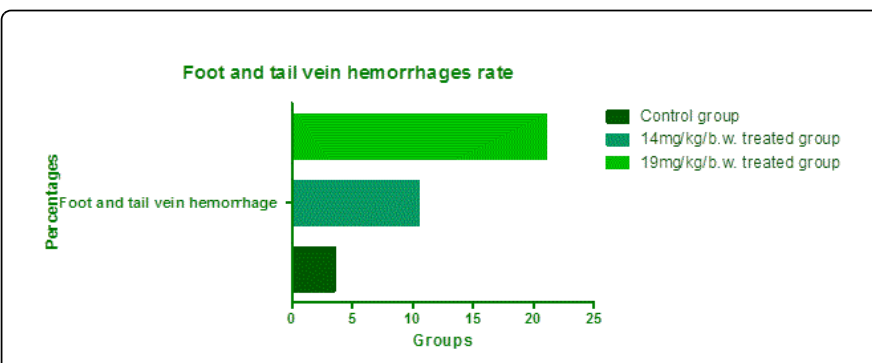

Figure 17: Represents Foot and tail vein hemorrhage rate in percentages from control and treated group.

\section{Tail vein hemorrhage}

Tail vein hemorrhages are evaluated from fetuses of control and same treated mother group. Treated group fetuses after Tail vein hemorrhage percentages evaluation compared with all fetuses of sham control group. Out of 57 fetuses from each group, $14 \mathrm{mg} / \mathrm{kg} /$ day bigger size AgNps colloidal solution treated group showed 8 (14.03\%) fetuses were suffered from Tail vein hemorrhage from $19 \mathrm{mg} / \mathrm{kg} /$ day bigger size AgNps colloidal solution treated group showed 14 (24.56\%) fetuses were suffered from Tail vein hemorrhage.

Control group also showed very negotiable percentages of Tail vein hemorrhage rate and compared well with treated groups. (4 fetuses found Tail vein hemorrhage from each control group) (7.01\%) (Figures 18 and 19).

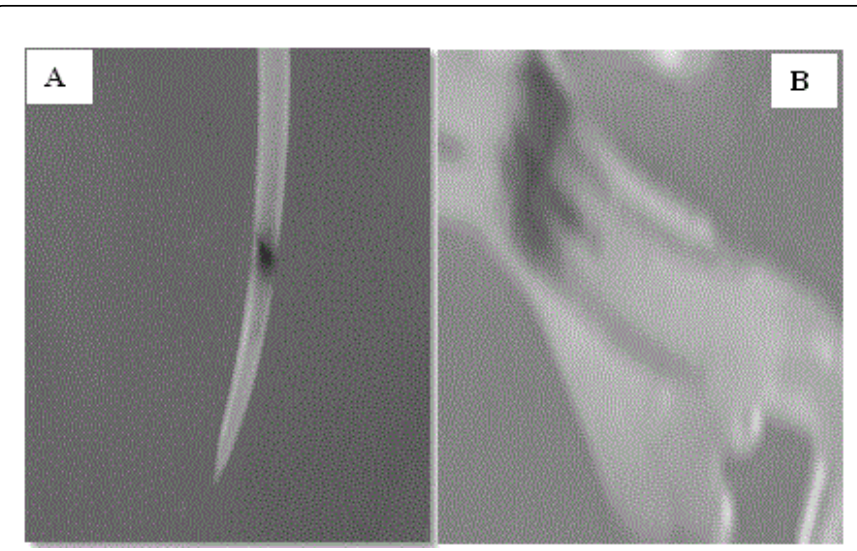

Figure 18: (A) Tail vein hemorrhage from $14 \mathrm{mg} / \mathrm{kg} / \mathrm{b} . w$. AgNps group, B Tail vein hemorrhage from $19 \mathrm{mg} / \mathrm{kg} / \mathrm{b}$.w. AgNps group.

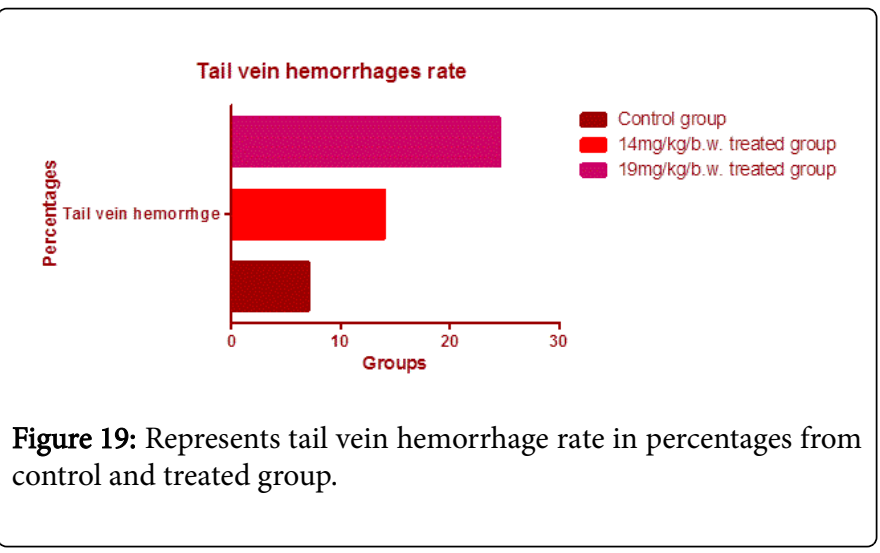

\section{Omphalocele}

Omphaloceles are evaluated from fetuses of control and same treated mother group. Treated group fetuses after Omphalocele percentages evaluation compared with all fetuses of sham control group. Out of 57 fetuses from each group, $14 \mathrm{mg} / \mathrm{kg} /$ day bigger size AgNps colloidal solution treated group showed 4 (7.01\%) fetuses were suffered from Omphalocele from $19 \mathrm{mg} / \mathrm{kg} /$ day bigger size AgNps colloidal solution treated group showed 6 (10.52\%) fetuses were suffered from Omphalocele. Control group also showed very negotiable percentages of Tail vein hemorrhage rate and compared well with treated groups ( 2 fetuses found Omphalocele from each control group) (3.50\%) (Figures 20 and 21) 
Citation: Prakash PJ, Royana S, Sankarsan P (2018) Multi-Organ Teratogenesis Sequels of Bigger Size Particles Colloidal Silver in Primate Vertebrates. J Cytol Histol 9: 501. doi:10.4172/2157-7099.1000501

Figure 20: (A) Omphalocele from 19 mg/kg/b.w. AgNps group.

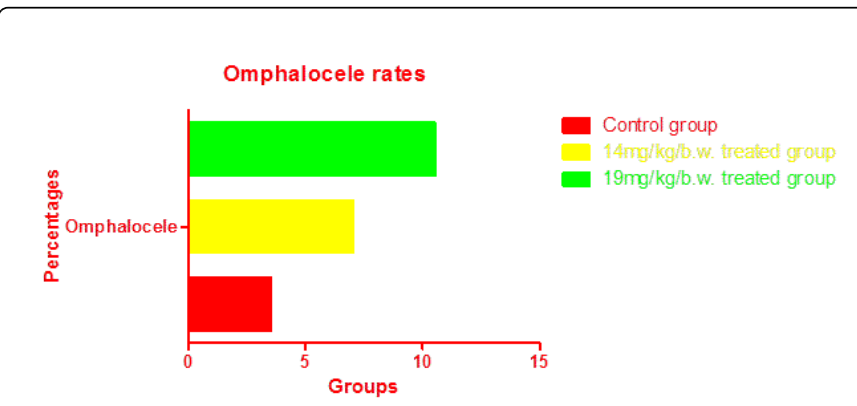

Figure 21: Represents Omphalocele rate in percentages from control and treated group.

\section{Bidiscoidal placental anomaly}

Bidiscoidal placental anomalies are evaluated from fetuses of control and same treated mother group. Treated group fetuses after Bidiscoidal placental anomaly percentages evaluation compared with all fetuses of sham control group. Out of 61 fetuses from each group, $14 \mathrm{mg} / \mathrm{kg} /$ day bigger size AgNps colloidal solution treated group showed 6 (9.83\%) fetuses were suffered from Bidiscoidal placental anomaly from 19 $\mathrm{mg} / \mathrm{kg} /$ day bigger size AgNps colloidal solution treated group showed $9(14.75 \%)$ fetuses were suffered from Bidiscoidal placental anomaly.
Control group also showed very negotiable percentages of Bidiscoidal placental anomaly rate and compared well with treated groups (3 fetuses found Bidiscoidal placental anomaly from each control group) (4.91\%) (Figures 22-24).

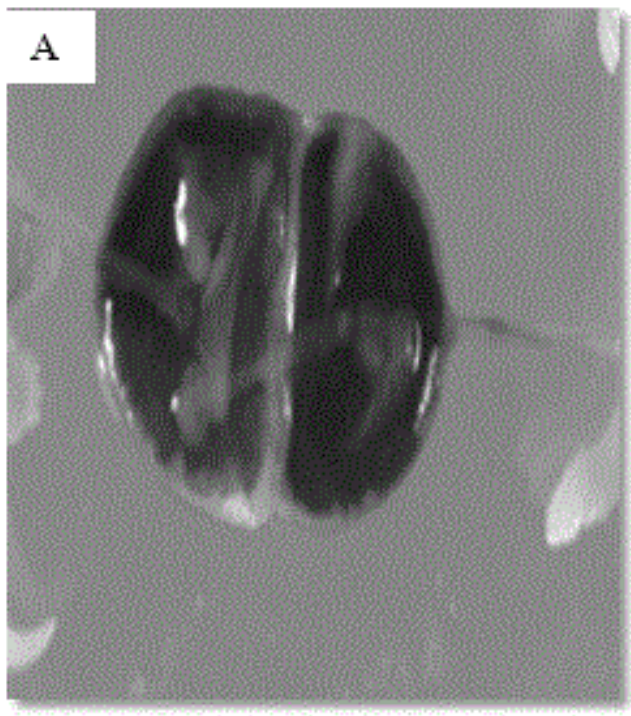

Figure 22: (A) Bidiscoidal placental anomaly from $19 \mathrm{mg} / \mathrm{kg} / \mathrm{b} . \mathrm{w}$. AgNps group.

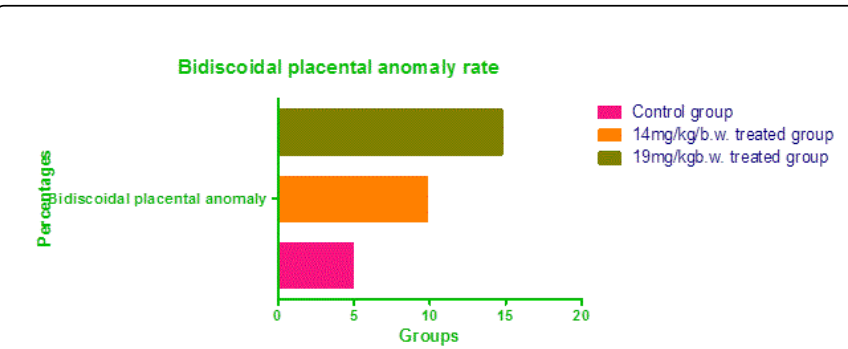

Figure 23: Represents Bidiscoidal placental anomaly rate in percentages from control and treated group. 
Citation: Prakash PJ, Royana S, Sankarsan P (2018) Multi-Organ Teratogenesis Sequels of Bigger Size Particles Colloidal Silver in Primate Vertebrates. J Cytol Histol 9: 501. doi:10.4172/2157-7099.1000501

Page 10 of 18

Overall analytical graph of all anomalies

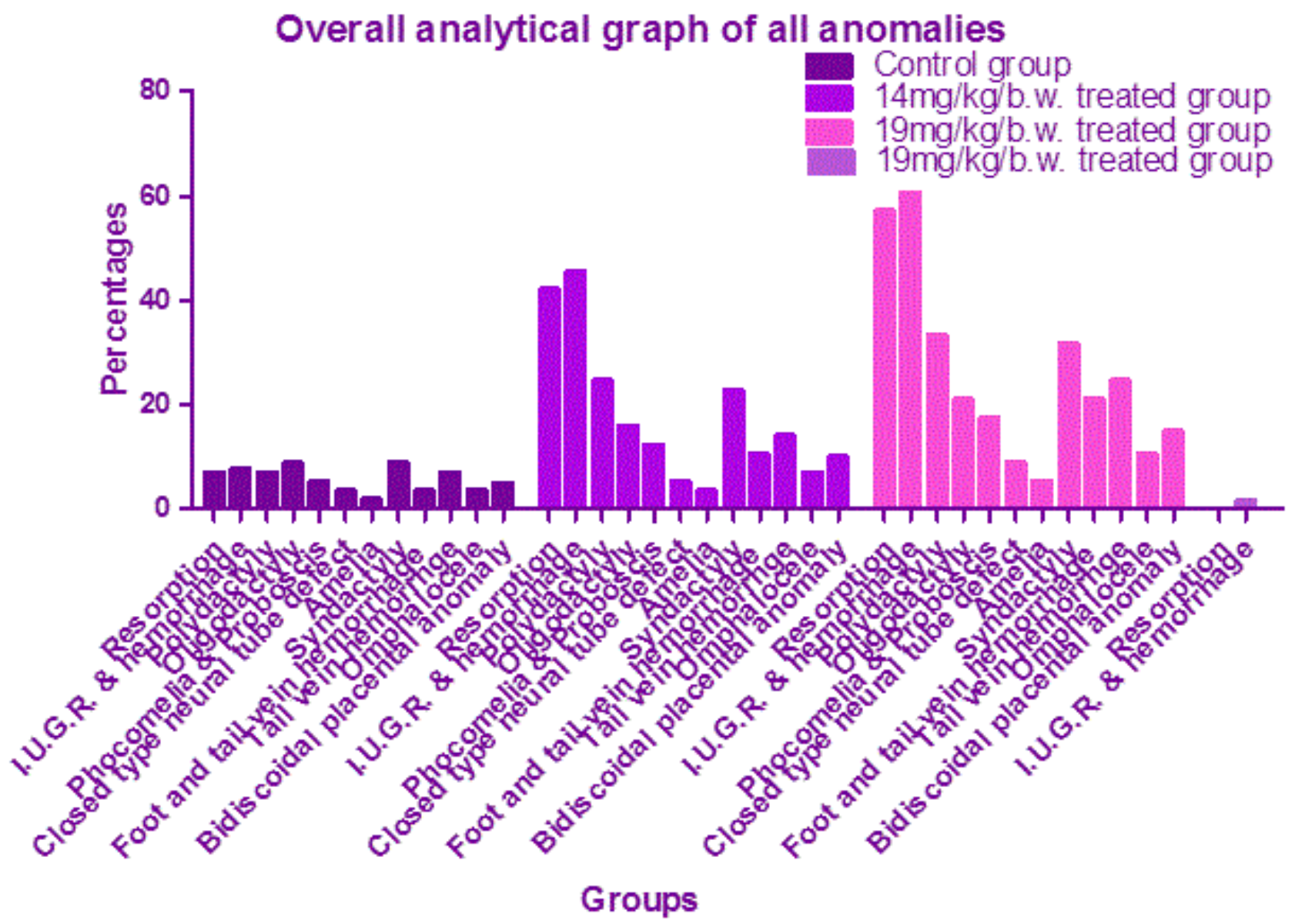

Figure 24: Represents overall analytical graph for all anomalies.

Individual calculated percentages of various fetal body malformations summarized in analytical bar diagram showed that the intensity of all integrated embryological malformations increased with increase in dose of bigger size silver nano particles through repeated maternal oral gavages exposure whereas the percentage of normal decrease.

\section{Overall malformation number and percentages in tabular} form

Individual calculated percentages of various fetal body malformations summarized in Table 1 also showed that the intensity of major embryological malformations increased with increase in dose of bigger size silver nano particles through repeated maternal oral gavages exposure whereas the percentage of normal mildly increase.

\begin{tabular}{|c|c|c|}
\hline Groups & $\begin{array}{l}\text { Type of fetus body malformations (Total no. of } \\
\text { fetuses) }\end{array}$ & Percentages \\
\hline Control group & $\begin{array}{l}\text { a) Resorption (7) } \\
\text { b) I.U.G.R. (5) }\end{array}$ & $\begin{array}{l}7.00 \% \\
7.57 \%\end{array}$ \\
\hline $\begin{array}{l}14 \text { mg/kg/day } \\
\text { AgNps Tr. Gr. }\end{array}$ & $\begin{array}{l}\text { a) Severe IUGR with external hemorrhages } \\
\text { (31) } \\
\text { b) Syndactyly(13), oligodactyly(9), extended limb } \\
\text { anomalies with IUGR (5) } \\
\text { c) Resorption (42) } \\
\text { d) I.U.G.R. (30) }\end{array}$ & $\begin{array}{l}46.56 \% \\
15.78 \%+22.80 \%=38.58 \% \\
14.95 \% \\
42.00 \% \\
45.45 \%\end{array}$ \\
\hline $\begin{array}{l}19 \mathrm{mg} / \mathrm{kg} / \mathrm{day} \\
\text { AgNps Tr. Gr. }\end{array}$ & a) Omphalocele with IUGR (6) & $10.52 \%$ \\
\hline
\end{tabular}


Citation: Prakash PJ, Royana S, Sankarsan P (2018) Multi-Organ Teratogenesis Sequels of Bigger Size Particles Colloidal Silver in Primate Vertebrates. J Cytol Histol 9: 501. doi:10.4172/2157-7099.1000501

Page 11 of 18

\begin{tabular}{l|l} 
b) Bidiscoidal placental anomalies with & $14.75 \%$ \\
IUGR(9) & $57.00 \%$ \\
c) Resorption (57) & $60.60 \%$ \\
d) I.U.G.R. (40) &
\end{tabular}

Table 1: Summarizes total number of fetuses, type of fetus body malformations and their percentages from different groups.

\section{Number and percentages of live fetuses' estimation}

Live fetuses percentages analysis which mention in Table 2 indicates the overall calculated percentages increased with increase of dose of bigger size silver nano colloidal solution as repeated oral gavages (Table 3).

\begin{tabular}{|l|l|l|l|l|}
\hline SI. No. & Dose & Mother no. of & Total no. of fetuses & Live fetuses No. of \\
\hline 1 & Control & 10 & 100 & $97(96.29 \%)$ \\
\hline 2 & $14 \mathrm{mg}$ tr.gr. & 10 & 57 & $43(70.49 \%)$ \\
\hline 3 & $19 \mathrm{mg}$ tr.gr. & 10 & 57 & $33(57.89 \%)$ \\
\hline
\end{tabular}

Table 2: Summarizes dose, total number of mothers, total number of fetuses, number of absorption, number of live fetuses.

Overall number of embryological malformations in tabular form

Number of live fetuses of control and treated group from Table 2 analysis shows the number of live fetuses' percentages decreases from control group to 14 and $19 \mathrm{mg} / \mathrm{kg} /$ day treated group. Analysis of all figures shows the mean percentages of various malformations progressively increases from control towards 14 and $19 \mathrm{mg} / \mathrm{kg} / \mathrm{day}$ group. Overall percentages of IUGR also found increased from control towards 14 and $19 \mathrm{mg} / \mathrm{kg} /$ day group.

\begin{tabular}{|l|l|l|l|l|l|l|l|l|l|l|l|}
\hline \multicolumn{2}{|l|}{ Malformations } \\
\hline
\end{tabular}

Table 3: Summarizes the numbers of malformations from different groups.

F.N.- IUGR-Intra Uterine Growth Retardation $/{ }^{*}$ L. M.-Limb malformation $/{ }^{*}$ CNTD-Close type

neural tube defect $/{ }^{*}$ FTVH-Foot and tail vein hemorrhage $/^{*}$ TVH - Tail vein hemorrhage $/^{*}$ S. D. O. D. E. L. A. Syndactyly, oligodactyly, extended limb anomaly $/^{*}$ S. E. H. W. B-Severe external hemorrhages within body $/^{*}$ Ompha.-Omphalocele $/{ }^{*}$ B. D. P. A.-Bidiscoidal placental anomaly.

\section{Crown rump length and weight estimation of control and} treated fetuses

Significant differences in body weight (Table 4) were observed between the control and treated groups. At the scheduled autopsy, no treatment-related gross findings were observed in mothers of any group.

\begin{tabular}{|l|l|l|l|}
\hline SI. No. & Dose & $\begin{array}{l}\text { Mean } \pm \text { S.D. of CRL } \\
\text { (Crown rump length of fetuses in } \\
\text { mm.) }\end{array}$ & $\begin{array}{l}\text { Mean } \pm \text { S.D. of weight } \\
\text { of live fetuses in gm. }\end{array}$ \\
\hline 1 & Control & $271 \pm 15.16$ & $1.254 \pm 0.002$ \\
\hline 2 & $14 \mathrm{mg} / \mathrm{kg} / \mathrm{day}$ & $149 \pm 5.01$ & $0.731 \pm 0.001$ \\
\hline
\end{tabular}



$19 \mathrm{mg} / \mathrm{kg} / \mathrm{day}$ $109 \pm 3.21$ $0.700 \pm 0.001$

Table 4: Summary of data analyses shows the mean \pm s.d. of crown rump length and weight of live fetuses decreases progressively from control towards 14 and $19 \mathrm{mg} / \mathrm{kg} /$ day group and with increase in dose of bigger size silver nano colloidal solution as repeated oral gavages.

A values are presented as Means $\pm \mathrm{SD}(\mathrm{gm}){ }^{*}$ Insignificant difference at $\mathrm{p}>0.05$ level when compared with the control group.

\section{Skeletal malformations}

The individual skeletal malformation percentages also calculated from control, 14 and $19 \mathrm{mg} / \mathrm{kg} / \mathrm{b} . \mathrm{w} /$ day bigger size silver nano colloidal solution repeated oral gavages treated group (100 fetuses from each group). The percentage of skeletal malformations was found higher and highest in $14 \mathrm{mg}$ AgNps and $19 \mathrm{mg} \mathrm{AgNps} / \mathrm{kg}$ b.w treated group pups when compared with the control group fetuses (100 control fetuses were selected for experiment and mild percentage of skeletal malformations calculated from control group was $9 \%$ ).

Among $14 \mathrm{mg} / \mathrm{kg} / \mathrm{b}$.w./day bigger size AgNps treated group 10 pups were observed absence or complete loss of cervical vertebrae with or complete loss of 12th rib and rest of the vertebrae were observed undeveloped and dysmorphic spinous process, Metatarsal cleft or gap is also seen on dorsal or reversal view of foot of one of the fetus, unossified hip bone on ventral or front view with absence of segment and fibrosis is also seen, un-ossified temporal bone which is found fibroses on lateral view of skull, absence of proximal segment of innominate bone, vertebral column anomaly was seen with rudimentary 6th and 9th rib and absence of 10th, 11th and 12th is observed ribs in one of the fetus, un-ossified parietal bone was also seen, Anencephaly with scoliosis vertebrae was seen in L1-L5 in one of the fetus, un-ossified hip bone was seen, un-ossified and undeveloped scapulae of both side was seen on dorsal or back view of one of the fetus, Absence of cartilage was seen from 6 th to 12 th rib in one of the fetus. The percentage of skeletal malformations calculated in this group was $63 \%$.

The $19 \mathrm{mg} / \mathrm{kg}$ b.w AgNps treated group fetuses were presented highest or peak percentage of skeletal malformations (79\%). Scoliosis was seen in lumbar region in one of the fetus, one fetus demonstrated un-ossified or undeveloped occipital bone, un-ossified or undeveloped scapulae and hip bone, big fibrosis is observed in maxilla, frontal and parietal bones, same is also observed in second to sixth segment of sternum., cleft is observed in the ankle joint, increased space is observed between 1st and 2 nd rib and 5th to 8th ribs of left side of one of the fetus, also cleft is observed in symphisis pubis joint of one of the fetus, un-ossified mandibular hypoplasia, absence of spinous process with wavy ribs is also observed, in one fetus we observed complete fusion of the 2 nd to 8 th cervical vertebrae which is clearly differentiated from rest of the 1st cervical vertebrae. We also observed mild scoliosis and un-ossified occipital and parietal bone and absence of scapulae on right side of one of the fetus, hypo plastic vertebrae is also seen (Figure 25).

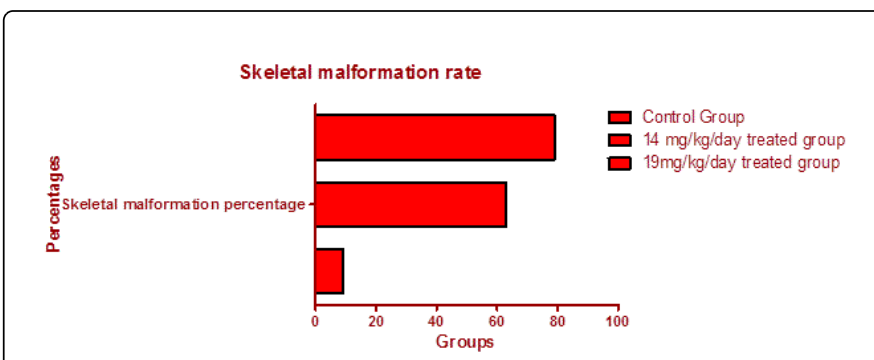

Figure 25: Represents skeletal malformation rate from control and treated group.

\section{Neural teratogenicity}

Higher and highest dose (14 and $19 \mathrm{mg} / \mathrm{kg} /$ day) bigger size AgNps treated group 100 fetuses each including control group demonstrated accumulated silver nano and neural cells micro fragment reaction products outside and inside of nuclear envelop, rough endoplasmic reticulum (RER) and endocytotic vesicle of neuronal cells. It was proved to be neuronal cell teratogenic effects such as astrocytic swelling, honey comb deformity of Basket, Betz and Lugaro cells along with degeneration and dysmorphology of all histological layers of developing cerebrum, cerebellum and hippocampus.

Neural histochemistry of fetal cortex by Golgi staining procedure showed reduction of number of dendrite arborisation and unipolar neuron with basket cells degeneration and dysmorphology. But the intensity of such was found almost higher in higher dose (68\%) and highest in highest dose (89\%) and concentration. Both the treated group was well compared with the sham control group (9\%) (Figures 26 and 27). 
Citation: Prakash PJ, Royana S, Sankarsan P (2018) Multi-Organ Teratogenesis Sequels of Bigger Size Particles Colloidal Silver in Primate Vertebrates. J Cytol Histol 9: 501. doi:10.4172/2157-7099.1000501

Page 13 of 18
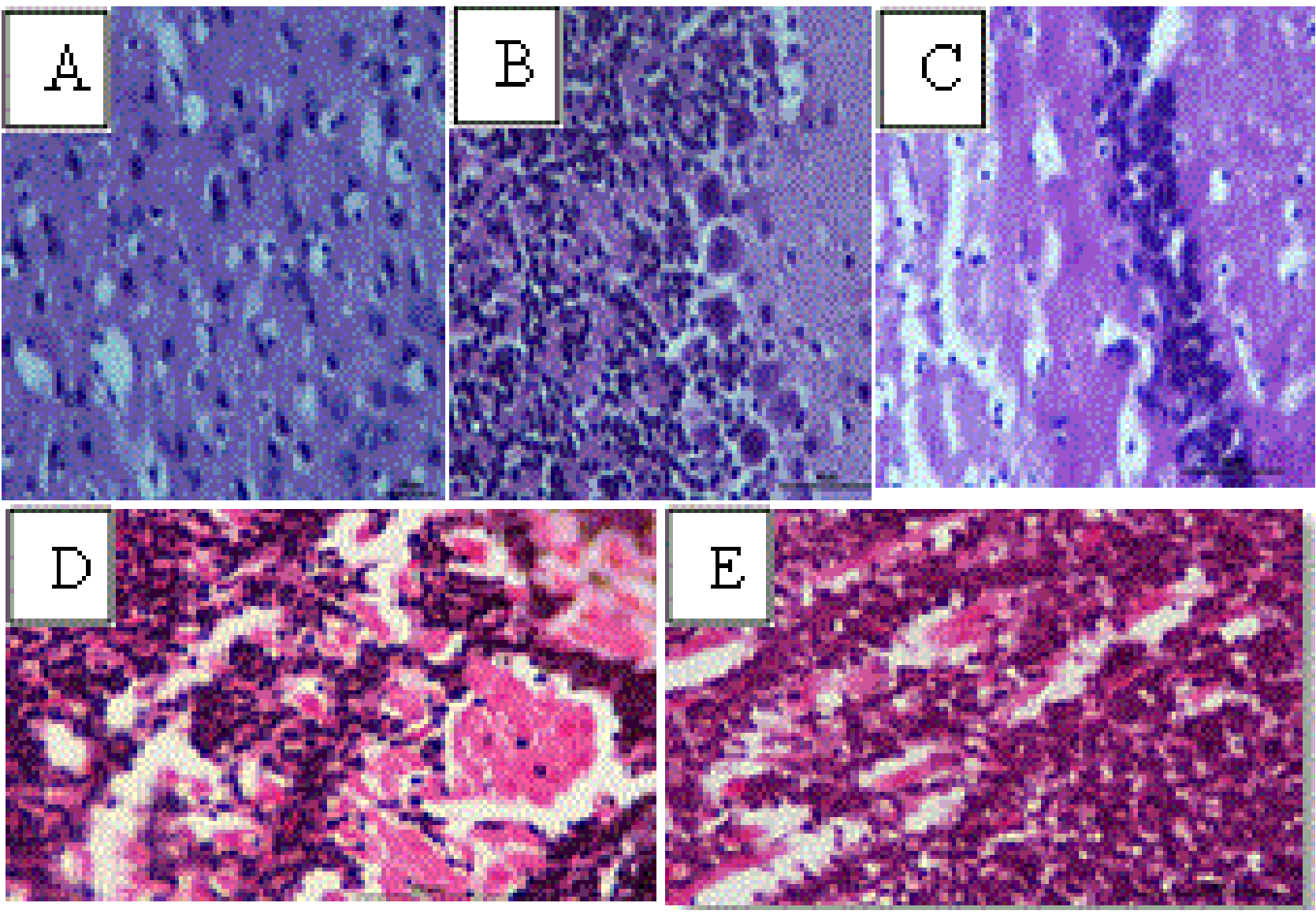

Figure 26: (A) Histology of cerebrum showing honey comb deformity in granular layer, Degeneration in the form of reduction in the thickness of external molecular layer, external and internal granular layer, small and large pyramidal cell layer found, neurons found highly swelled in higher group and moderately swelled in lower group (40x), Acute cell blebbing, honeycomb cell shape deformity and necrosis of granule cell observed of mother mice after $19 \mathrm{mg} / \mathrm{kg} / \mathrm{b}$.w. bigger size nano silver colloidal solution treatment, (B) Histology of cerebellum showing honey comb deformity in molecular layer, molecular and Glial cell layer Swelling, Multiple hemorrhagic focus, Corticomedullary degeneration with shrunkening of Thick granular layer, Inerneuron and Golgi cell layer, degeneration of lugaro cells in unipolar brush cell layer, Degeneration of Purkinje cell and granule cells with their reduction in number in comparison to the control, disturbance in the normal pattern of mossy fiber, parallel fiber found in $14 \mathrm{mg} / \mathrm{kg}$ b.w. mother cerebellum showed severe degeneration or even absence of Purkinje cells and tissue contour and continuity is found lossed of mother mice along with degeneration of and dysmorphology of Purkinje cell layer after $19 \mathrm{mg} / \mathrm{kg} / \mathrm{b} . \mathrm{w}$. bigger size nano silver colloidal solution treatment (C) Histology of mother hippocampus showing Corticomedullary degeneration with shrunkening of thick granular layer, Inerneuron and Golgi cell layer, degeneration of lugaro cells in unipolar brush cell layer, Degeneration of granule cells with their reduction in number, The single layer densely packed pyramidal neuron layer is found highly swelled and gradually reducing in number after $19 \mathrm{mg} / \mathrm{kg} / \mathrm{b}$.w. bigger size nano silver colloidal solution treatment (D) Histology of $14 \mathrm{mg}$ treated group fetus brain showed Increased amount of acute cellular blebbing, increased amount of hemorrhagic focus, inflammation of granular and Glial cells, $19 \mathrm{mg}$ treated group fetus brain showed same thing but the intensity found increases. It also showed severe dysmorphology of red nucleus. 


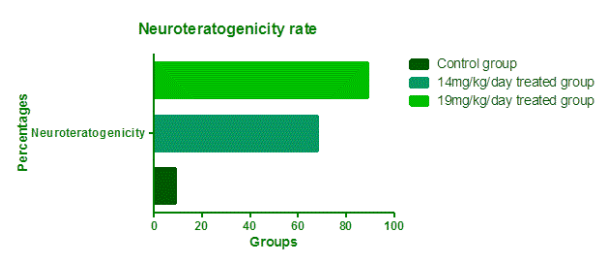

Figure 27: Represents neuroteratogenicity rate from control and treated group.

\section{Discussion}

Nano silver shows predominant antimicrobial activity along with antifungal but teratogenic sequels of bigger size silver nano seems to be new discovery after thorough review of activity in the recent and far past history about silver nano. Bigger size silver nano become major diagnostic tool for cancer like life threatening diseases [46,47]. Bacterial cell wall is dumped by bigger size silver nano. Though it possess potential antimicrobial activity, prolonged application and exposure to bigger size silver nano causes intensive diseases like Argyria and Argyrosis which is a major teratogenic effect described in far past history about silver ion. According to an eminent scientist's reporting the uptake of bigger size silver nano into the primate vertebrate body is often much higher teratogenic consequence when it is injected orally as a medication than from occupational exposure [48]. Most of the factory survey reports involvement of colloidal bigger size nano silver compounds, which application mostly causes teratogenic effects at even lower and medium concentrations or at higher concentration than metallic and insoluble silver compounds. For an example, blood-silver concentrations [49,50], several cross sectional studies were carried out and it was reported that Argyria is the most frequent teratogenicity adverse outcome from exposure to bigger size nano silver [51], in past research reporting was done that the long time oral repeated ingestion of bigger size nano silver containing drugs causes change of color in the skin and a blue-grey appearance on the face. Along with these symptoms some other symptoms like hypertension, diabetes, gastro esophageal reflux disease, benign prostatic hypertrophy and post-traumatic stress disorders were also observed. But in some cases, many of the company workers complained of decreased vision at night. Many ophthalmologic studies have been conducted and they have concluded that decreased vision at night is associated with the deposition of bigger size nano silver compound in the cornea in dispersed form [52-54]. It is obvious that bigger size silver nano particles possess unique teratogenicity arousal behavior. Finally for bigger size silver, whether nano-sized or not, there are always the problems of Argyria and Argyrosis in humans and eutrophication in the environment which is nothing but a range of teratogenicity arousal nature.

Hardly there is availability of data on the teratogenicity of bigger size nano silver upon F1 generation primate vertebrate embryos, the teratogenic effects of bigger size nano silver on multi system upon primate vertebrate embryos was evaluated in the present study for the first time. From past some researchers reported, F1generation primate vertebrate embryos exposed to bigger size nano silver showed moderate pleural swelling [55,56]. Ingestion of silver or ionisable silver compounds in pregnancy is a cause of infertility, impaired fetal growth, or abnormal development in any species. Silver nitrate (1\%) administered by intrauterine injection to 13 cynomolgus monkeys between 27 and 43 days of pregnancy caused early vaginal bleeding and termination of pregnancy, but two of seven animals that re-mated became pregnant again and delivered healthy offspring [57]. Two of the eminent nano scientist in 1934 observed argyria as predominant teratogenic response of the bigger size silver ion, which was reported for the first time by in a woman who had ingested a total dose of 6 to 7 g bigger size silver nitrate solution over a 1-year period of time and showed Argyria symptoms after the first six months of exposure. Another famous nano silver scientist also experimented irritation of respiratory tract, pain in abdomen and diminished night vision in workers exposed to silver nitrate solution and silver oxide dusts in a consumer product manufacture company over one to ten years. An experimental health worker engulfed bigger size colloidal silver nano two to three times per year for last two years and showed endocrine disruptions as teratogenic focuses, such as Hyperlipidemia, hypertension and diabetes as well as blue-grey facial signs. Neurologic teratogenicity is a rare and unusual consequence of bigger size nano silver colloid which was evidenced in recent year in a 70 to 80 -year-old male health worker who had a past history of self-medication with bigger size colloidal silver and was affected by myoclonic seizures. In conclusion, the present study showed the teratogenic effects of bigger size nano silver on multi system of body in F1 generation Swiss Albino mouse embryo. The present study results indicate that repeated oral gavages exposure of 14 and $19 \mathrm{mg} / \mathrm{kg} / \mathrm{b}$.w of bigger size silver nano particles colloidal solution for 7 to 18 days of gestation in Pregnant Swiss albino mice arises multi system teratogenicity in F1 generation embryos of treated pregnant mice. In this study, we tried to identify the adverse effects of bigger size AgNps using F1 generation mice embryo treated with repeated oral administration of bigger size nano silver colloidal solution.

We also evaluated multisystem teratogenicity rate in body of F1 generation mice embryos in percentages. We found when pregnant mice treated with bigger size AgNps colloidal solution in repeated oral gavages form, bigger-size AgNps were accumulated in multi organ which are intra-abdominal and intra peritoneal causes multisystem teratogenicity in F1 generation mice embryos after crossing blood placental barrier in pregnant mother mice. When pregnant mice were treated with bigger size AgNps colloidal solution in repeated oral gavages form, such bigger size AgNps translocated to blood embryos through the blood placental barrier and distributed throughout the multi organs, to arise teratogenicity focuses. According to this study, bigger size AgNps were also known to induce multi system teratogenicity in F1 generation embryo fetuses of pregnant mice like resorption, intra uterine growth retardation, limb malformation which includes polydactyl, oligodactyly, Phocomelia and proboscis, closed type neural tube deformity, Amelia, external limb mal formation such as Syndactyly, foot and tail vein hemorrhage, tail vein hemorrhage, bidiscoidal placental anomaly, live fetuses drop rate in bigger size AgNps treated group, skeletal malformation, neural teratogenicity like blood-brain barrier (BBB) destruction and astrocyte swelling, and caused neuronal degeneration. In our study, pregnant mice were treated with bigger size AgNps colloidal solution (71 to $1900.8 \mathrm{~nm}$ range) by repeated oral gavages administration from gestational day 7 to 18 and on 19th gestational day fetuses were removed after ventral laparotomy. In each embryological ailment we found the intensity and rate of percentages increased by increase of dose in each oral gavage. (Details are mention in result section) When we go for comparing to the small-sized AgNps (71 nm) with the largest-sized AgNps (1900.8 $\mathrm{nm})$ large size AgNps were not accumulated more in brain in 
comparison to other system as per histological and TEM view. It means that bigger size nano silver penetrate blood-brain barrier and blood placental barrier.

The size and dose dependent penetration bigger size AgNps through the tissue membrane of multi system of fetuses' body was also found intensity of rate or percentages of malformation directly proportional to dose. The result obtained in our study showed that it seemed to be more efficient for the large-sized AgNps to translocate into circulatory system and to be accumulated in organs after crossing blood brain and blood placental barrier. An eminent scientist suggested that the hypertrophy of the primate vertebrate heart was caused by high blood pressure due to the deposition of bigger size silver in the basement membranes of the renal glomeruli [58]. Teratogenic effects on the female reproductive system, changes in ovarian nuclear and cytoplasmic cell morphology were found in mice administered 0.01 to $0.03 \%$ ranges bigger size AgNps silver nitrate freshly prepared solution in the drinking water for 15 days to 1 month. (Corresponding to 20 to $25 \mathrm{mg}$ of silver/kg of b.w./day) [59]. A group of eminent and capable nano scientists investigated embryo teratogenicity in female mice embryos that had been repeatedly orally administered 40 to $50 \mathrm{mg}$ of silver chloride per embryo (Corresponding to 170 to $200 \mathrm{mg}$ of silver/kg of b.w./day) during gestational days 1-20 of the term. Postinterstitial implantation lethality was found to be increased in percentages as per increase of dose, and the incidence of visceral morphology damage in the offspring was considerably higher compared to the control group. Moreover, all of the newborns died within $24 \mathrm{~h}$ of birth [60]. Some other scientist after cumbersome experiment reported that an increase in percentages of lividity was observed in mice embryos given bigger size nano silver nitrate solution in the drinking water at a dose of 0.01 to $0.03 \%$ ranges for 2 to 4 months [60]. A group of world famous scientists investigated the teratogenic effects of the oral administration of ionic and $71 \mathrm{~nm}$ nano particulate silver which is bigger size for 28 days on neurotransmitters in rat embryos at a dose of 2.25 to $2.50 \mathrm{mg} / \mathrm{kg}$ of b.w/day ranges of nano particulate silver and 10 to $12 \mathrm{mg} / \mathrm{kg}$ of b.w/day of ionic silver (the lowest ionic silver dose investigated), and they found drastic elevations in nor-adrenaline, dopamine and 5-HT concentrations level in the brain [61]. An oldest and eminent nano scientist observed myoclonic status epilepticus in young man as teratogenic effect after the oral ingestion of excessive amounts of colloidal silver of bigger size [62].

Bigger size silver nanoparticle ingestion causes detrimental effect on embryo fetus development. It also causes various malformations in fetuses when they grow in womb. The deleterious effects visualizes when they born after maternal exposure of bigger size AgNps in prenatal stage. The various malformations fetus met with are limb malformations, snot mal development, virulent hemorrhages within the body, mid gut loop Herniation like Omphalocele, Bidiscoidal placental anomaly, close type neural tube defect, resorption, intra uterine growth retardation, Syndactyly, oligodactyly, foot and tail vein hemorrhages. These malformations hamper fetal weight, nutrition and crown rump length of fetuses. Various animal tests are done till today for sorting out the cause of malformations in fetus after silver nanoparticle ingestion through various routes. Maternal repeated oral exposure of bigger size AgNps in pregnant Swiss albino mice dams also causes various malformations in fetuses which are for the first time reported in our experiment. The oral ingestion tests of silver nanoparticles on maternal body cause's arousal of various malformations in exteriorized fetuses which increases in percentages with increase in dose. The data of present study says when 14 and 19 $\mathrm{mg} / \mathrm{kg} /$ day bigger size silver nanoparticle colloidal solution is injected to pregnant Swiss albino mice it causes arousal of culminative toxicity in fetuses with various malformations. The percentages of such malformations increase with increase in dose of bigger size silver nanoparticles. Resorption is a common form of gross anomaly which increases with increase in dose of bigger size AgNps and the increased percentages was evaluated in our study with the increase in dose (14 $\mathrm{mg} / \mathrm{kg} /$ day treated group $=42 \%, 19 \mathrm{mg} / \mathrm{kg} /$ day treated group=57\%) though control group showed minimal percentage of resorption (7.00\%). Intra uterine growth retardation is a common form of gross anomaly which visualizes in fetuses while conducting the present study and increases with increase in dose of bigger size AgNps and the increased percentages was evaluated in our study with the increase in dose $(14 \mathrm{mg} / \mathrm{kg} /$ day treated group $=45.45 \%, 19 \mathrm{mg} / \mathrm{kg} /$ day treated group $=60.60 \%$ ) though control group showed minimal percentage of Intra uterine growth retardation (7.00\%). Limb malformation like Polydactyl and Oligodactyly are special form of teratogenic anomalies which visualizes in $\mathrm{F} 1$ generation mice embryos while giving repeated oral dose of bigger size AgNps colloidal solution to pregnant Swiss Albino mice mother and increases with increase in dose and the increased percentages was evaluated in our study with the increase in dose $(14 \mathrm{mg} / \mathrm{kg} /$ day treated group $=24.56 \%$ (Polydactyl), $15.78 \%$ (Oligodactyly); $19 \mathrm{mg} / \mathrm{kg} /$ day treated group $=33.33 \%$ (Polydactyl), $21.05 \%$ (Oligodactyly)) though control group showed minimal percentage of Limb malformation like Polydactyl and Oligodactyly (7.01\%=Polydactyl; $8.77 \%=$ Oligodactyly). Phocomelia and Proboscis are common form of teratogenic anomaly which visualizes in F1 generation embryo fetuses while giving repeated oral dose of bigger size AgNps colloidal solution to pregnant Swiss Albino mice mother and increases with increase in dose of bigger size AgNps and the increased percentages was evaluated in our study with the increase in dose $(14 \mathrm{mg} / \mathrm{kg} /$ day treated group $=12.28 \%, 19 \mathrm{mg} / \mathrm{kg} /$ day treated group $=17.54 \%$ ) though control group showed minimal percentage of Phocomelia and Proboscis (5.26\%). Closed type neural tube deformity is common form of teratogenic anomaly which visualizes in F1 generation embryo fetuses while giving repeated oral dose of bigger size AgNps colloidal solution to pregnant Swiss Albino mice mother and increases with increase in dose of bigger size AgNps and the increased percentages was evaluated in our study with the increase in dose $(14 \mathrm{mg} / \mathrm{kg} /$ day treated group $=5.26 \%, 19 \mathrm{mg} / \mathrm{kg} /$ day treated group $=8.77 \%$ ) though control group showed minimal percentage of closed type neural tube deformity (3.5\%).

Amelia is also a rare form of teratogenic anomaly which visualizes in $\mathrm{F} 1$ generation embryo fetuses while giving repeated oral dose of bigger size AgNps colloidal solution to pregnant Swiss Albino mice mother and increases with increase in dose of bigger size AgNps and the increased percentages was evaluated in our study with the increase in dose $(14 \mathrm{mg} / \mathrm{kg} /$ day treated group $=3.5 \%, 19 \mathrm{mg} / \mathrm{kg} /$ day treated group $=5.26 \%$ ) though control group showed minimal percentage of Amelia (1.75\%). External limb anomaly like Syndactyly is also a common form of teratogenic anomaly which visualizes in F1 generation embryo fetuses while giving repeated oral dose of bigger size AgNps colloidal solution to pregnant Swiss Albino mice mother and increases with increase in dose of bigger size AgNps and the increased percentages was evaluated in our study with the increase in dose $(14 \mathrm{mg} / \mathrm{kg} / \mathrm{day}$ treated group=3.5\%, $19 \mathrm{mg} / \mathrm{kg} /$ day treated group $=5.26 \%$ ) though control group showed minimal percentage of External limb anomaly like Syndactyly (1.75\%). Foot and tail vein hemorrhage is common form of gross anomaly which visualizes in F1 generation embryo fetuses while giving repeated oral dose of bigger 
and smaller size AgNps colloidal solution to pregnant Swiss Albino mice mother and increases with increase in dose of bigger and smaller size AgNps and the increased percentages was evaluated in our study with the increase in dose $(14 \mathrm{mg} / \mathrm{kg} /$ day treated group $=10.52 \%, 19$ $\mathrm{mg} / \mathrm{kg} /$ day treated group $=21.05 \%)$ though control group showed minimal percentage of Foot and tail vein hemorrhage (3.5\%). Simple tail vein hemorrhage is common form of gross anomaly which visualizes in F1 generation embryo fetuses while giving repeated oral dose of bigger and smaller size AgNps colloidal solution to pregnant Swiss Albino mice mother and increases with increase in dose of bigger and smaller size AgNps and the increased percentages was evaluated in our study with the increase in dose $(14 \mathrm{mg} / \mathrm{kg} /$ day treated group $=14.03 \%, 19 \mathrm{mg} / \mathrm{kg} /$ day treated group $=24.56 \%)$ though control group showed minimal percentage of simple tail vein hemorrhage (7.01\%). Omphalocele is rare form of teratogenic anomaly which visualizes in F1 generation embryo fetuses while giving repeated oral dose of bigger size AgNps colloidal solution to pregnant Swiss Albino mice mother and increases with increase in dose of bigger AgNps and the increased percentages was evaluated in our study with the increase in dose $(14 \mathrm{mg} / \mathrm{kg} /$ day treated group $=7.01 \%, 19 \mathrm{mg} / \mathrm{kg} /$ day treated group $=10.52 \%$ ) though control group showed minimal percentage of Omphalocele (3.5\%). Bidiscoidal placental anomaly is also a common form of teratogenic anomaly which visualizes in F1 generation embryo fetuses while giving repeated oral dose of bigger size AgNps colloidal solution to pregnant Swiss Albino mice mother and increases with increase in dose of bigger AgNps and the increased percentages was evaluated in our study with the increase in dose $(14 \mathrm{mg} / \mathrm{kg} /$ day treated group $=7.01 \%, 19 \mathrm{mg} / \mathrm{kg} /$ day treated group $=10.52 \%$ ) though control group showed minimal percentage of Bidiscoidal placental anomaly $(4.91 \%)$.

The calculated percentages are seen progressively increasing with increase in dose of bigger size AgNps as a consequence of this, percentages of live fetuses decreased progressively with increase in dose $(14 \mathrm{mg} / \mathrm{k}$. g./b.w./day treated group $=70.49 \% ; 19 \mathrm{mg} / \mathrm{k} . \mathrm{g} . / \mathrm{b} . \mathrm{w} /$ day treated group $=57.89 \%$ ) where control group also showed maximum percentages (96.29\%), (Table 2). Also the calculated mean \pm s.d. are seen progressively decreasing with increase in dose of bigger size AgNps as a consequence of this, calculated mean \pm s.d of crown rump length of fetuses decreased progressively with increase in dose $(14 \mathrm{mg} /$ k.g./b.w./day treated group $=149 \pm 5.01 ; 19 \mathrm{mg} / \mathrm{k} . \mathrm{g} . / \mathrm{b} . \mathrm{w} /$ day treated group $=109 \pm 3.21)$ where control group also showed maximum percentages $(271 \pm 15.16)$, (Table 3$)$. The calculated mean \pm s.d are seen progressively decreasing with increase in dose of bigger size AgNps as a consequence of this, calculated mean \pm s.d of weight of fetuses decreased progressively with increase in dose $(14 \mathrm{mg} / \mathrm{k}$. g./ b.w./day treated group $=0.731 \pm 0.001 ; 19 \mathrm{mg} / \mathrm{k}$.g./b.w/day treated group $=0.700 \pm 0.001$ ) where control group also showed maximum percentages (1.254 \pm 0.002$)$, (Table 3 ). Multiple skeletal malformation is also a common form of teratogenic anomaly which visualizes in F1 generation embryo fetuses while giving repeated oral dose of bigger size AgNps colloidal solution to pregnant Swiss Albino mice mother and increases with increase in dose of bigger AgNps and the increased percentages was evaluated in our study with the increase in dose (14 $\mathrm{mg} / \mathrm{kg} /$ day treated group $=63 \%, 19 \mathrm{mg} / \mathrm{kg} /$ day treated group=79\%) though control group showed minimal percentage of Multiple skeletal malformation (9\%). Multiple skeletal malformation is also a common form of teratogenic anomaly which visualizes in $\mathrm{F} 1$ generation embryo fetuses while giving repeated oral dose of bigger size AgNps colloidal solution to pregnant Swiss Albino mice mother and increases with increase in dose of bigger AgNps and the increased percentages was evaluated in our study with the increase in dose $(14 \mathrm{mg} / \mathrm{kg} /$ day treated group $=63 \%, 19 \mathrm{mg} / \mathrm{kg} /$ day treated group $=79 \%$ ) though control group showed minimal percentage of Multiple skeletal malformation (9\%). Neural teratogenicity is also a common form of teratogenic anomaly which visualizes in F1 generation embryo fetuses while giving repeated oral dose of bigger size AgNps colloidal solution to pregnant Swiss Albino mice mother and increases with increase in dose of bigger AgNps and the increased percentages was evaluated in our study with the increase in dose $(14 \mathrm{mg} / \mathrm{kg} /$ day treated group $=68 \%, 19 \mathrm{mg} / \mathrm{kg} /$ day treated group $=89 \%$ ) though control group showed minimal percentage of Multiple skeletal malformation (9\%). Rest of the gross malformations like limb malformations, snot mal development, proboscis, phocomelia, virulent hemorrhages within the body, mid gut loop herniation like omphalocele, bidiscoidal placental anomaly, close type neural tube defect, syndactyly, oligodactyly, foot and tail vein hemorrhages and simple tail vein hemorrhages also seen increases in terms of percentages with increase in dose of bigger size silver nano particles. An exceptional growth of percentages of malformations like severe IUGR and external body hemorrhages within the body was met in the fetuses of $14 \mathrm{mg} / \mathrm{kg} /$ day treated group during the course of experiment $(1.51 \%)$ number and percentages of live fetuses seen decreasing with increase in dose of AgNps. Though there is hardly any data available regarding assessment of gross teratogenic anomalies of fetuses by bigger silver nanoparticle colloidal solution after repeated maternal exposure testing our study confirms strong evidence that bigger size silver nano particles certainly shows deleterious effects in fetuses after maternal oral exposure. For researcher benefit and public awareness over ignorance the potential adverse effects of bigger size nano silver administration has been reported teratogenic in many studies which also includes experiment with chicken embryos, but present study "AgNps effects on fetus gross anomalies" tries to convince 14 and $19 \mathrm{mg} / \mathrm{kg} /$ day bigger silver nanoparticles of 71 to $1900.8 \mathrm{~nm}$ size range bigger size silver nanoparticle colloidal solution repeated oral administration and testing definitely have deleterious effects on embryo-fetus development which cause gross anomalies in fetuses of Swiss albino dams. It confirms repeated oral gavages silver nanoparticle colloidal solution testing on animals in pregnancy cause hampers of fetus natural growth in womb and fetus body morphology is insulted by this, and resulted in abnormal development.

\section{Conclusion}

Repeatedly oral administered bigger size nano silver colloidal solution has been described and proved to be absorbed and accepted by tissue space in a range of $2-20 \%$ in mammals with a human value of $19 \%$. It is also proved to be teratogenic in multi system of primate vertebrate embryo body where percentages of such teratogenicity increase with increase in dose and size of nano silver. Based on above findings in primate vertebrate pregnant Swiss Albino mice embryo animals, bigger size nano silver seems to be distributed to all of the organs and cause multi system teratogenic sequels. In the skin, nano silver induces a blue-grey discoloration termed Argyria. The following size and dose-dependent animal teratogenicity findings have been reported: fatality, loss of lividity, crown rump length and weight though insignificant. Hypo activity of skeletal system and nervous system with arouse teratogenic consequences, neural teratogenicity also occurs when it is induced in repeated oral dose form. Sufficient data exists suggesting that the effects induced by particulate bigger size nano silver are mediated via silver ions that are released from the particle surface. With the present data regarding, a margin of safety calculation indicates bigger size nano silver should be used in a 
controlled manner with minimum or moderate dose and size while performing manufacture of consumer products.

\section{Declarations}

\section{Ethical approval and consent to participate}

All procedures performed in studies involving animal participants were in accordance with the ethical standards of the institutional and/or national research committee and its later amendments or comparable ethical standards. The studies were performed with the approval of the Central Animal Ethical Committee of the Banaras Hindu University Varanasi (No./Dean/2014/CAEC/614).

\section{Consent for publication}

All authors read the final manuscript and approved manuscript for publication.

\section{Competing interests}

There is no competing of interest in opinion between 1st author and 2nd author also with corresponding author.

\section{Funding}

This study was supported by minor division scheme 5012 funds of Banaras Hindu University.

\section{Acknowledgements}

All authors acknowledge University Grant Commission for its immense support.

\section{References}

1. Toshima N (2003) Nano scale Materials. In: Liz M, Marzan L, Kamat PV (eds.) Kluwer Academic Pub, London, pp: 79-96.

2. Gupta A, Silver S (1998) Silver as biocide: Will resistance become a problem?, Nat Biotechnol 16: 888 .

3. Tkachenko AG, Xie H, Coleman D (2003) Multifunctional gold nanoparticle peptide complexes for nuclear targeting. J Am Chem Soc 125: 4700-4701.

4. Lockman PR, Koziara JM, Mumper RJ (2004) Nanoparticle surface charges alter blood brain barrier integrity and permeability. J Drug Target 12: 635-641.

5. Chang AL, Khosravi V, Egbert B (2006) A case of argyria after colloidal silver ingestion. J Cutaneous Pathol 33: 809-811.

6. McIntyre E, Wilcox J, McGill J (2001) Silver toxicity in an infant of strict vegan parents. J Pediatr Gastroenterol Nutr 33: 501-502.

7. Ohbo Y, Fukuzako H, Takeuchi K (1996) Argyria and convulsive seizures caused by ingestion of silver in a patient with schizophrenia. Psychiatry Clin Neurosci 50: 89-90.

8. Loeschner K, Hadrup N, Qvortrup K (2011) Distribution of silver in rats following 28 days of repeated oral exposure to silver nanoparticles or silver acetate. Part Fibre Toxicol 8: 18.

9. Van der Zande M, Vandebriel RJ, Van DE (2012) Distribution, elimination, and toxicity of silver nanoparticles and silver ions in rats after 28-day oral exposure. ACS Nano 6: 7427-7442.

10. Goebel HH, Muller J (1973) Ultra structural observations on silver deposition in the choroid plexus of a patient with argyria. Acta Neuropathol 26: 247-251.
11. Olcott CT (1947) Experimental argyrosis 3-Pigmentation of the eyes of rats following ingestion of silver during long periods of time. Am J Pathol 23: 783-791.

12. Olcott CT (1948) Experimental argyrosis 4-Morphologic changes in the experimental animal. Am J Pathol 24: 813-833.

13. Olcott CT (1950) Experimental argyrosis; hypertrophy of the left ventricle of the heart in rats ingesting silver salts. AMA Arch Pathol 49: 138-149.

14. Olcott CT, Richter GW (1958) Experimental argyrosis VI. Electron microscopic study of ingested silver in the kidney of the rat. Lab Invest 7: 103-109.

15. Pereira G (1977) Localization of silver in the spleen of argyric rats by energy dispersive X-ray analysis coupled with scanning and transmission electron microscopy. Proc-Annu Meet Electron Microsc Soc Am 35: 504-505.

16. Rungby J (1986) Experimental argyrosis: ultrastructural localization of silver in rat eye. Exp Mol Pathol 45: 22-30.

17. Rungby J, Danscher G (1983) Localization of exogenous silver in brain and spinal cord of silver exposed rats. Acta Neuropathol 60: 92-98.

18. Van der Zande M, Vandebriel RJ, Van DE (2012) Distribution, elimination, and toxicity of silver nano particles and silver ions in rats after 28-day oral exposure. ACS Nano 6: 7427-7442.

19. Walker F (1971) Experimental argyria: a model for basement membrane studies. Br J Exp Pathol 52: 589-593.

20. Walker F (1972) The deposition of silver in glomerular basement membrane. Virchows Arch B Cell Pathol 11: 90-96.

21. Lee Y, Choi J, Kim P (2012) A transfer of silver nanoparticles from pregnant rat to offspring. Toxicol Res 28: 139-141.

22. East BW, Boddy K, Williams ED (1980) Silver retention, total body silver and tissue silver concentrations in argyria associated with exposure to an anti-smoking remedy containing silver acetate. Clinical Exp Dermatol 5: 305-311.

23. Matuk Y, Ghosh M, McCulloch C (1981) Distribution of silver in the eyes and plasma proteins of the albino rat. Can J Ophthalmol 16: 145-150.

24. Tamimi SO, Zmeili SM, Gharaibeh MN (1998) Toxicity of a new antismoking mouthwash 881,010 in rats and rabbits. J Toxicol Environ Health 53: 47-60.

25. Walker F (1971) Experimental argyria: a model for basement membrane studies. Br J Exp Pathol 52: 589-593.

26. Olcott CT (1950) Experimental argyrosis. Hypertrophy of the left ventricle of the heart in rats ingesting silver salts. Arch Pathol 49: 138-149.

27. Sardari RRR, Zarchi SR, Talebi A (2012) Toxicological effects of silver nanoparticles in rats. Afr J Microbiol Res 6: 5587-5593.

28. Finnell RH (1999) Teratology: General Considerations and principles. J Allerg Clin Immunol 103: 337-342.

29. Giavini E, Menegola E (2004) Gene-teratogen chemically induced interactions in congenital malformations. Biol Neonate 85: 73-81.

30. De santis M, Straface J, Carducci B (2004) Risk of drug-induced congenital defects. Eur. J Obestet Gynecol Reprod Biol 117: 9-10.

31. Park E, Bae E (2010) Repeated-dose toxicity and inflammatory responses in mice by oral administration of silver nanoparticles. Environ Toxicol Pharm 30: 162-168.

32. Sharma HS, Ali SF, Hussain SM (2009) Influence of engineered nanoparticles from metals on the blood brain barrier permeability, cerebral blood flow, brain edema and neurotoxicity. An experimental study in the rat and mice using biochemical and morphological approaches. J Nanosci Nanotechnol 9: 5055-5072.

33. Sharma HS, Ali SF, Tian ZR (2009) Chronic treatment with nanoparticles exacerbate hyperthermia induced blood-brain barrier breakdown, cognitive dysfunction and brain pathology in the rat. Neuroprotective effects of nano wired-antioxidant compound H-290/51. J Nanosci Nanotechnol 9: 5073-5090.

34. Langford D, Masliah E (2001) Crosstalk between components of the blood brain barrier and cells of the CNS in microglial activation in AIDS. Brain Pathol 11: 306-312. 
35. Sharief MK, Ciardi M, Thompson EJ (1992) Blood-brain barrier damage in patients with bacterial meningitis: association with tumor necrosis factor-alpha but not interleukin-1 beta. J Infect Dis 166: 350-358.

36. Sharief MK, McLean B, Thompson EJ (1993) Elevated serum levels of tumor necrosis factor-alpha in Guillain-Barre syndrome. Ann Neurol 33: 591-596.

37. Beaumont A, Marmarou A, Fatouros P (2002) Secondary insults worsen blood brain barrier dysfunction assessed by MRI in cerebral contusion. Acta Neurochir Suppl 81: 217-219.

38. Benn T, Cavanagh B, Hristovski K (2010) The release of nano silver from consumer products used in the home. J Environ Qual 39: 1875-1882.

39. Sawosz E, Grodzik M, Zielinska M (2009) Nanoparticles of silver does not affect growth, development and DNA oxidative damage in chicken embryos. Arch Geflugelk 73: 208-213.

40. McCauley RL, Li Y, Chopra V (1994) Cytoprotection of human dermal fibroblasts against silver sulfadiazine using recombinant growth factors. J Surg Res 56: 378-384.

41. Blumberg H, Carey TN (1934) Argyremia: Detection of unsuspected and obscure argyria by the spectrographic demonstration of high blood silver. J Am Med Assoc 103: 1521-1524.

42. Rosenman KD, Moss A, Argyria KS (1979) Clinical implications of exposure to silver nitrate and silver oxide. J Occup Med 21: 430-435.

43. Moss AP, Sugar A, Hargett NA (1979) The ocular manifestations and functional effects of occupational argyrosis. Arch Opthhalmol 97: 906-908.

44. Williams N (1999) Longitudinal medical surveillance showing lack of progression of argyrosis in a silver refiner. Occup Med 49: 397-399.

45. Chang ALS, Khosravi V, Egbert B (2006) A case of argyria after colloidal silver ingestion. J Cutan Pathol 33: 809-811.

46. Tang J, Xi T (2008) Status of biological evaluation on silver nanoparticles 25: 958-961.

47. Stepien K, Morris R, Brown S (2009) Unintentional silver intoxication following self-medication: an unusual case of corticobasal degeneration. Ann Clin Biochem 46: 520-522.

48. Margaret IP, Lui SL, Poon VKM (2006) Antimicrobial activities of silver dressing: an in-vitro comparison. J Med Microbiol 55: 59-63.
49. Sarkar S, Jana AD, Samanta SK (2007) Facile synthesis of silver nano particles with highly efficient antimicrobial property. Polyhedron 26: 4419-4426.

50. Drake PL, Hazelwood KJ (2005) Exposure related health effect of silver and silver compounds. A review. Ann Occup Hyg 49: 575-585.

51. William N, Gardener I (1995) Absence of symptoms in silver refiners with raised blood silver levels 45: 205-208.

52. Armitage SA, White MA, Wilson HK (1996) The determination of silver in whole blood and its application to biological monitoring of occupationally exposed groups. Ann Occup Hyg 40: 331-338.

53. Bouts BA (1999) Images in clinical medicine. Argyria. N Eng J med 340: 1554.

54. Gulbranson SH, Hud JA, Hansen RC (2000) Argyria following the use of dietary supplements containing containing colloidal silver protein. Cutis, pp: $373-376$

55. Tomi NS, Kranke B, Aberer W (2004) A silver man. Lancet, p. 532

56. Stebounova LV, Adamcakova-Dodd A, Kim JS (2011) Nanosilver induces minimal lung toxicity or inflammation in a subacute murine inhalation model. Part Fibre Toxicol 8: 5.

57. Kim YS, Song MY, Park JD (2010) Sub chronic oral toxicity of silver nano particles. Part Fibre Toxicol 6: 20

58. Hadrup N, Loeschner K, Bergstrom A (2012) Sub acute oral toxicity investigation of nanoparticulate and ionic silver in rats. Arch Toxicol 86: 543-551.

59. Hadek R (1966) Preliminary report on the cellular effect of intra vital silver in the mouse ovary. J Ultrastruct Res 15: 66-73.

60. Shavlovski MM, Chebotar NA, Konopistseva LA (1995) Embryo toxicity of silver ions is diminished by ceruloplasmin-further evidence for its role in the transport of copper. Bio Metals 8: 122-128.

61. Hadrup N, Loeschner K, Mortensen A (2012) The similar neurotoxic effects of nano particulate and ionic silver in vivo and in vitro. Neurotoxicology 33: 416-423.

62. Mirsattari SM, Hammond RR, Sharpe MD (2004) Myoclonic status epilepticus following repeated oral ingestion of colloidal silver. Neurology 62: $1408-1410$ 